NBER WORKING PAPER SERIES

\title{
EFFECTS OF COPYRIGHTS ON SCIENCE - EVIDENCE FROM THE US BOOK REPUBLICATION PROGRAM
}

\author{
Barbara Biasi \\ Petra Moser \\ Working Paper 24255 \\ http://www.nber.org/papers/w24255 \\ NATIONAL BUREAU OF ECONOMIC RESEARCH \\ 1050 Massachusetts Avenue \\ Cambridge, MA 02138 \\ January 2018
}

We wish to thank seminar participants at the Becker Friedman Institute, Berkeley, Columbia, Copenhagen, CUNY, the Economic History Association, the European Economic Association, EPIP, the Federal Trade Commission, Harvard, London Business School, Munich, MIT, NBER, Odense, Rutgers, Science Po, the US Department of Justice, NYU, Rutgers, Zurich, as well as Lionel Bently, Chris Buccafusco, Kirk Doran, Glenn Ellison, Paul Heald, Margaret Kyle, Ryan Lampe, Frank Mueller-Langer, Abishek Nagaraj, Armin Schmutzler, Fabian Waldinger, and Thomas Wollmann for helpful comments. We are particularly grateful to Jim Edwards for sharing company records and letters for the J.W. Edwards Company, and to Kathleen Smith for searching for historical copies of BRP books at Stanford's Green Library. Jacob Hartwig, Hailey Kwon, Mark Walsh, and Jason Weitze provided outstanding research assistance. Moser gratefully acknowledges financial support from the National Science Foundation through CAREER grant 1151180 and from INet's Grant for Copyright and Creativity. Biasi gratefully acknowledges support from the Gregory Terrill Cox Fellowship and the John M. Olin Program in Law and Economics at Stanford Law. The views expressed herein are those of the authors and do not necessarily reflect the views of the National Bureau of Economic Research.

NBER working papers are circulated for discussion and comment purposes. They have not been peer-reviewed or been subject to the review by the NBER Board of Directors that accompanies official NBER publications.

(C) 2018 by Barbara Biasi and Petra Moser. All rights reserved. Short sections of text, not to exceed two paragraphs, may be quoted without explicit permission provided that full credit, including $\odot$ notice, is given to the source. 
Effects of Copyrights on Science - Evidence from the US Book Republication Program

Barbara Biasi and Petra Moser

NBER Working Paper No. 24255

January 2018

JEL No. L82,N34,N42,O15,O34,O38,O43

\begin{abstract}
$\underline{\text { ABSTRACT }}$
Copyrights for books, news, and other types of media are a critical mechanism to encourage creativity and innovation. Yet economic analyses continue to be rare, partly due to a lack of experimental variation in modern copyright laws. This paper exploits a change in copyright laws as a result of World War II to examine the effects of copyrights on science. In 1943, the US Book Republication Program (BRP) granted US publishers temporary licenses to republish the exact content of German-owned science books. Using new data on citations, we find that this program triggered a large increase in citations to German-owned science books. This increase was driven by a significant reduction in access costs: Each 10 percent decline in the price of BRP book was associated with a 43 percent increase in citations. To investigate the mechanism by which lower book prices influence science, we collect data on library holdings across the United States. We find that lower prices helped to distribute BRP books across US libraries, including less affluent institutions. Analyses of the locations of citing authors further indicate that citations increased most for locations that gained access to BRP books. Results are confirmed by two alternative measures of scientific output: new PhDs and US patents that use knowledge in BRP books.
\end{abstract}

\author{
Barbara Biasi \\ Louis A. Simpson International Building \\ Princeton University \\ Princeton, NJ 08544 \\ bbiasi@princeton.edu \\ Petra Moser \\ Department of Economics \\ NYU Stern \\ 44 West 4th Street \\ New York, NY 10012 \\ and NBER \\ pmoser@stern.nyu.edu
}

An online appendix is available at http://www.nber.org/data-appendix/w24255 
Copyrights for books, news, and other types of media are a crucial mechanism for promoting creativity and innovation. Yet, with a few recent exceptions, economic analyses of copyrights continue to be rare. ${ }^{1}$ Empirical tests face two major challenges: First, the extreme length of modern copyrights (nearly 100 years in Europe and the United States) makes it difficult to observe all but exceptionally durable content off copyright. Second, there is almost no experimental variation in modern copyright laws because changes in copyrights typically occur in response to lobbying, reflected in names like the 1998 US "Mickey Mouse Protection Act" and the European Union's 2011 "Cliff (Richard's) Law."

To address these issues, existing work has exploited quasi-experimental variation in copyright piracy, and found no significant effects on sales or on the quality of popular music (e.g., Oberholzer-Gee and Strumpf 2007, Rob and Waldfogel 2006, Danaher et al. 2014). Complementary analyses of historical copyright laws indicate that basic levels of copyrights - not exceeding the life of the authors - can encourage creativity. Starting from low levels, extensions in copyright lengths have increased payments to authors, and allowed men from lower social classes to enter the profession of writing (MacGarvie and Moser 2013). In $19^{\text {th }}$ century Italy, a subset of states adopted copyrights due to idiosyncratic variation in the timing of Napoleon's military victories. Comparisons of opera creation across Italian states with and without copyrights suggest that the adoption of basic copyright laws increased both the number and the quality of music (Giorcelli and Moser 2017).

Yet, copyrights may also cause tremendous losses in consumer welfare by restricting access to existing work (e.g., Varian 2005). Like monopolies for traditional goods, copyrights for content create temporary monopolies that impose deadweight loss. ${ }^{2}$ Confirming this theory, Heald (2014) and Reimers (2015) show that books which are slightly less than 95 years old, and therefore still on copyright, are less likely to be available for sale today than books that are slightly older than 95 and therefore off copyright. ${ }^{3}$

Copyrights may create additional welfare loss when they limit or discourage the reuse of content in future creativity and innovation. In principle, these losses should be particularly high for science, a field in which the creation of new, cumulative innovation

\footnotetext{
${ }^{1}$ For example, Reimers (2015), Cagé, Hervé, and Viaud (2017), and Nagaraj forthcoming. A well-developed legal literature has examined the welfare effects of copyrights in theoretical analyses (for example, Landes and Posner 1989, and Menell 1989), and more recently in empirical work (Buccafusco and Springman 2010, DiCola 2013).

${ }^{2}$ Standard models of patent laws (such as Nordhaus 1969) focus on the tradeoffs between this deadweight loss and the positive incentive effects that exclusive rights create for patentees.

${ }^{3}$ Extensions in the length of copyright terms have also been shown to raise the price of copyrighted content, by improving publishers' ability to price discriminate (Li et al. 2016).
} 
depends critically on access to existing work (Scotchmer 1991). Analyses of patents, as an alternative type of intellectual property, have shown that mechanisms which limit the power of patents can discourage cumulative invention (Galasso and Schankerman 2015, Moser and Voena 2012). Research on privately owned non-patent intellectual property (IP) has found that such IP discouraged scientific research on the human genome (Williams 2013). Nevertheless, neither of these results generalize to copyrights, which create a fundamentally different type of IP. Compared with patents, copyrights are much more narrow and long-lived.

Recent work on textbooks has shown that books are a powerful tool to shape attitudes and beliefs (Cantoni et al. 2017). ${ }^{4}$ Historical research on encyclopedias has found that the density of subscribers was a strong predictor of city growth after the onset of the French industrial revolution (Squicciarini and Voigtländer 2017), working through innovation as a mechanism. For scientific papers, a growing interdisciplinary literature on open access has shown that articles which are available for free tend to become more heavily cited, suggesting that open access can encourage cumulative science. ${ }^{5}$ Based on this idea, funding agencies increasingly require grant recipients to make research available for free, essentially ignoring copyrights. ${ }^{6}$ McCabe and Snyder $(2014,2015)$, however, find that even basic controls for article quality reduce the correlation between open access and future citations, highlighting the need for additional analyses that address the issue of selection. ${ }^{7}$

This paper addresses selection by comparing changes in new scientific citations to the same book. Moreover, our research design enables us to investigate the effects of reductions in price rather than imposing a price of zero. This feature is an important complement to existing research on open access, because policymakers may want to reduce price or subsidize access costs instead of enforcing a price of zero.

Our empirical design exploits a plausibly exogenous historical change in copyright policy as a result of World War II, under the Book Republication Program (BRP). In 1942, the US Alien Property Custodian appropriated all enemy-owned property in the United States, including German-owned copyrights for books. The Custodian issued temporary (6-month)

\footnotetext{
${ }^{4}$ Cantoni et al (2017) examine the effects of a major change in textbook curriculum, driven by China's government, between 2004 and 2010. They show that the change in curriculum caused significant changes in attitudes, improving China's governance and increasing skepticism toward free markets. Prat (2017) analyzes media power across platforms and shows that broadcasters can swing elections.

${ }^{5}$ For example, see the influential analyses of Eysenbach (2006) and Evans and Reimer (2009).

${ }^{6}$ See, for example Bill \& Melinda Gates Foundation Open Access Policy (http://www.gatesfoundation.org/howwe-work/general-information/open-access-policy, accessed December 3, 2015).

${ }_{7}^{7}$ Davis et al. (2008) avoid selection by randomly assigning articles to open access across 11 journals of the American Physiological Society. They find that scientists are more likely to download - but not cite - open access articles within 12 months. This window of observation, however, is probably too short to identify effects on follow-on science. Our approach addresses this issue by examining long-run changes in follow on science.
} 
licenses to US publishers, allowing them to republish the exact content of German-owned science books. ${ }^{8}$ At the end of the six-month period, copyrights reverted to the Custodian who could license the book again, effectively breaking the monopoly of the copyrights.

To investigate the effects of the BRP on science, we focus on a sample of 283 BRP books in chemistry and mathematics and 247 Swiss books in the same fields. ${ }^{9}$ For these books, we construct three alternative measures of science and innovation: citations by books and other scientific publications, new PhDs in mathematics, and new US patents that use knowledge in BRP books.

To address the issue of selection, we first compare changes in citations to the same BRP book from English-language authors and authors publishing in other languages. Most English-language authors were based in the United States and benefitted directly from the US-based BRP, whereas authors in other countries were less likely to benefit. OLS estimates indicate an additional 80 percent increase in citations to BRP books from English-language authors after 1942, compared with other authors. ${ }^{10}$

If, however, English-language authors published more after 1942, they would have also generated more citations, so that English-language citations to BRP books might have increased mechanically, independently of the BRP. To address this issue, we pursue a separate but complementary identification strategy, by comparing changes in citations by English-language authors to BRP books with changes in citations by English-language authors to Swiss books. Like German scientists, Swiss scientists were leaders in chemistry and mathematics, and they wrote primarily in German. Due to Switzerland's neutrality, however, books with Swiss-owned copyrights were not available to the BRP. OLS estimates of a matched sample of BRP and Swiss books confirm the substantial growth in new research citing BRP books.

Next, we combine the two identification strategies, by comparing the differential change in citations to BRP books from English-language and other authors with the same

\footnotetext{
${ }^{8}$ At a time when German continued to be a lingua franca of science (e.g., Ammon 2001), US publishers reprinted the original German text without translations. In the 1960s, many BRP books were translated to English, and citations to the English-language version replace citations to the BRP. Since our estimates only count citations to the original BRP books, this shift creates a downward bias in estimates for later years.

${ }^{9}$ The Custodian (1944) also lists 187 BRP books in physics. We exclude physics because many prominent physicists worked on secret projects, such as the Manhattan Project, and were not allowed to discuss their research with the outside world. Robert Oppenheimer and General Grove chose Los Alamos because as the site for the Manhattan project because it was a "site so isolated there was only a winding gravel road and one phone line into the place" (Bird and Sherwin 2006, p. 206).

${ }^{10}$ Confirming results in Moser, Voena, and Waldinger (2014), we find that citations to BRP books increased more for books by émigrés. The number of émigré books is, however, small and émigré books cannot explain the overall increase in citations.
} 
differential change for Swiss books. Triple-differences estimates imply an additional 67 percent increase in English-language citations to BRP books.

How did the BRP increase citations? The program's most dramatic immediate effect was a significant reduction in the price of BRP books. Before the BRP, the average BRP book sold for $\$ 43$, equivalent to $\$ 1,360.00$ in $2016 .{ }^{11}$ Under the BRP, US publishers distributed exact copies of the same book for 25 percent less on average. We exploit this change in price to examine the effects of access cost on cumulative science.

Predictions from a general production function for cumulative knowledge guide the empirical analysis. We show that scientists, who depend on access to existing knowledge, produce more new science when existing knowledge is cheap. Intensity estimates confirm this first prediction. Each 10 percent decline in the price of a BRP book is associated with 38 percent additional citations by English-language authors. Comparing English-language citations to BRP and Swiss books suggests that each 10 percent decline in price led to a 40 percent increase in citations to BRP books compared with Swiss books. Intensity tripledifferences estimates that combine the two identification strategies imply a 46 percent increase for each 10 percent decline in price.

A second implication of cumulative knowledge production is that the effects of lower prices should be larger for disciplines that are more dependent on human, rather than physical capital. To test this prediction, we compare the effects of price for mathematics and chemistry, two disciplines that varied greatly in their dependence on physical capital. Mathematicians, like David Hilbert, were able to create new work with little more than a pen and paper, whereas chemists required access to laboratory space and other types of physical capital. Regressions that compare mathematics with chemistry confirm differential effects of across disciplines: A 10 percent decline in price is associated with an additional 88 percent increase in citations for mathematics compared with chemistry.

How did lower book prices increase citations to BRP books? Without digital copies, scientists depend on access to physical copies of library books. ${ }^{12}$ A reduction in price should, in principle, have allowed more libraries to buy BRP books, and allow a new group of scientists to use these books in their research. Sales records of BRP publishers show that libraries bought many BRP books (Bokas and Edwards 2011, p. 25).

\footnotetext{
${ }^{11}$ Using real wage conversions, based on the unskilled wage, as a conservative estimate (Williamson 2016).

${ }^{12}$ For example, a major objection against Los Alamos as the site for the Manhattan Project was that "in the wilds of New Mexico" scientists lacked access to a decent library (John Manley, an experimental physicist cited in Bird and Shirwin (2005, p. 207). Also Hargittai (2006, pp. 89-131).
} 
To systematically examine the role of libraries, we construct data on historical library holdings from the National Union Catalog (NUC, 1968-1981). Intended as a search tool, the NUC captures the stock of all books that were available in American libraries in 1956. Our analysis of the NUC data suggest that the BRP helped to diffuse books across the United States, allowing less affluent institutions to purchase them. By 1956, a geographically and economically diverse set of US libraries held BRP books. At the same time, Swiss books remained concentrated in the holdings of two wealthy research libraries (Yale and Chicago).

Next, we investigate when scientists at new locations started to use BRP book. To perform this test, we collect information on loans of BRP books from lending cards that are attached to the back of library books. These data show a striking overlap between the time when a book was first used and our data on citations. Scientists begin to use BRP books around 1946, four years after the BRP. First loans of a book peak around 1955, a striking match to the increase in citations.

To further examine the mechanisms by which lower book prices encourage follow-on science, we connect the locations of citing authors with the locations of libraries that held BRP books. Because the location of BRP libraries is not selected at random, we cannot estimate causal effects in these tests, but the geographic evidence supports the main tests. Scientists within 25 miles of a BRP book began to cite BRP books more after 1942 than scientists who were further away. Estimates also attenuate with increasing distance from BRP books. Importantly, pre-trends in citations are comparable for nearby and distant locations.

Finally, we construct two alternatives measures for changes in follow-on science: New PhDs in mathematics and US patents that use knowledge in BRP books. Data on PhDs confirm the expansion in the geographic scope. An analysis of US patents indicates a 15 percent increase in patents that utilize BRP books. Importantly, there are no observable differences in the pre-trends of $\mathrm{PhD}$ theses or US patents across locations.

The remainder of the paper is structured as follows. Section I summarizes the relevant history and institutional details of the BRP. Section II describes the data on citations (including information on the location of authors), new $\mathrm{PhD}$ theses, and US patents. Section III presents our baseline estimates of the effects of the BRP. Section IV investigates the effects of changes in price. Section V presents an in-depth analysis of library holdings, along with a geographic analysis of changes in the location of citing authors, and their proximity to BRP books. Section VI explores alternative proxies for science such as the number of new $\mathrm{PhDs}$ in mathematics and patents, and Section VII concludes. 


\section{The World War II Book RepublicATION Program}

Until World War II, the United States had been a major buyer of German science books. In 1871, an international treaty had granted German and other foreign publishers the same protection as US publishers. ${ }^{13}$ As a result, German-owned copyrights were protected for a length of 56 years under the 1909 Copyright Act. ${ }^{14}$ At the onset of World War II, the President of the American Library Association Ralph Munn wrote to Secretary of State Hull

"Germany has made, and is making, many contributions to man's knowledge [...] The world of scholarship can not afford to be deprived of the German contribution to this knowledge" (cited in Richards 1981, p. 254).

In that year, the United States had spent a total of $\$ 1.5$ million ( $\$ 54.2$ million in year 2016 dollars) on foreign books and journals, mostly by German scientists (Richards 1981, p. 253).

In the early years of the war, US libraries continued to source German science books through agents in Switzerland and other neutral countries. In 1940, Thomas Fleming of the Columbia Medical School Library explained that "the British have been confiscating no publications sent to American libraries, and that is about all there is to the situation" (Richards 1981, p. 254). By mid 1941 the US Department of State prohibited money transfers to Germany, and Nazi Germany forbade its publishers to ship new orders of books. To secure continued access, the Federal Government's Interdepartmental Committee for the Acquisition of Foreign Publications (IDC) and the library-sponsored Joint Committee began to transfer German publications onto microfilm to distribute in the United States (Richards 1981, p. 255).

On July 6, 1942, President Roosevelt's Executive Order No. 9193 authorized the US Alien Property Custodian to "direct, manage, supervise, control or vest [...] Patents, patent applications, copyrights, copyright applications, trademarks, or trademark applications or rights" (Myron 1945, p. 76). Now a prominent group of librarians and scientists urged the Custodian to seize German-owned copyrights to reduce payments to Nazi Germany (Richards 1981, p. 255). Between 1942 and 1944, the Custodian seized more than 100,000 books with enemy-owned copyrights. ${ }^{15}$

\footnotetext{
${ }^{13}$ April 15, 1892, United States Copyright Office, Circular 38A. The 1892 treaty extended the 1891 International Copyright Act, which had granted copyrights to foreign books that had been typeset in the United States (Manufacturing Clause, Columbia Law Association 1950, p. 686).

${ }^{14}$ The 1909 Act extended copyrights to all works of authorship, including music (Varian 2005, p. 124), and increased copyright length from 14 to 28 years, renewable for an additional 28 years. These terms remained in place until the 1976 Copyright Act extended copyrights to 50 years after the author's death and 75 years for corporate owners. The 1998 Copyright Term Extension Act further extended terms to 70 years after death and 95 years for corporate owners. See Goldstein (2003) for the history of copyright law.

${ }^{15}$ Forty-sixth Annual Record of the Register of Copyrights 1944, p. 8.
} 
Starting in 1942, the Custodian allowed US publishers to bid for temporary licenses to republish exact copies of enemy-owned books (Myron 1945, p. 85). The 283 books in our data were published by a total of 36 publishers. Two publishers, Dover and J.W. Edwards, won the largest number of bids (Bokas and Edwards 2011, p. 22). J.W. Edwards had already bought German machines that allowed quick republication, and licensed 650 titles from the Alien Property Custodian (Bokas and Edwards 2011, p. 23). ${ }^{16}$ Licenses were limited to 6 months and non-extendable (Myron 1945, p. 85), so that publishers would face the threat of entry, effectively breaking the monopoly of copyrights. ${ }^{17}$

At a time when most US scientists were able to read German, US publishers simply reprinted the content of German-owned science books, without translating the text to English. The size of editions ranged between 200 and 500 copies (Bokas and Edwards 2011, p. 25). ${ }^{18}$ One of Edwards' publications was Frederick Konrad Beilstein's (1918) Handbuch der Organischen Chemie, "a critical tool for every organic chemist working in a lab until the early 1970s." Before the BRP, the German publisher Springer had sold the set for $\$ 2,000$ (equivalent to $\$ 63,000$ in 2016). ${ }^{19}$ Under the BRP, Edwards Brothers offered Beilstein "for $\$ 400$ a set, and the company sold more than 600 sets to laboratories, researchers, and academicians" (Bokas and Edwards, 2011 p. 25). The first English version of Beilstein appeared in 1960 (Luckenback, 1981). When an English-language substitute was available, citations to the original BRP version declined, creating downward bias in our estimates.

\section{DATA}

The main data set for our analysis include nearly 10,000 new articles and books that cite 283 BRP books and a control group of 247 Swiss books. For BRP books we have unique data on book prices under two copyright regimes, before and after the BRP. Complementary data include information on library holdings and usage data for library books. Two alternative measures capture changes in new PhDs theses across locations and over time, as well as US patents that use knowledge in BRP books.

\section{A. BRP Books and Price Data}

\footnotetext{
16 “...considerable royalties amounting to many thousands of dollars were accumulated and remitted to the U.S. Government for the benefit of the original copyright owner" (Bokas and Edwards 2011, p. 25).

${ }^{17}$ Menu costs from printing catalogues were substantial, so that publishers could not adjusting prices dynamically and instead charged a single price for each edition.

${ }^{18}$ J.W. Edwards alone published 700 books and 140 journals, "most of which have been published under license by the Alien Property Custodian Office." (Bokas and Edwards 2011, p. 23).

${ }^{19}$ Using unskilled wage labor value conversions, Williamson 2016.
} 
We collect the full list of BRP books from a 1944 publication of the Alien Property Custodian Office: Book Republication Program: Titles Suggested for Republication, an Alphabetical List with a Subject Index. For 334 books, including 274 in chemistry and 60 in mathematics, the Custodian (1944, pp. 1-102) lists the title, author, research field, publication year, and publication city. ${ }^{20}$ The first book in alphabetical order is

Aberhalden, Emil, Handbuch der Biologischen Arbeitsmethoden. Abt. 3: Physikalischchemische Methoden. Berlin, Springer, 1928-30.3 vols. Field: Chemistry, Physical and Theoretical. Original price: \$128.00. Reproduction: \$84.50, set. Licensee: J.W. Edwards.

The average BRP book was 5 years old in 1944. Without the BRP, German publishers would have had the exclusive right to print copies of this book for another 51 years. ${ }^{21}$

The Custodian lists the BRP price charged by US publishers for all 334 books. For 319 BRP books (96 percent), the Custodian also lists the original price immediately before the BRP. ${ }^{22}$ Under the pre-BRP copyright regime, German publishers sold 319 books for an average of $\$ 41.40$ (equivalent to $\$ 1,300$ in 2016, Appendix Figure A1).

Under the BRP, book prices declined by an average of 24.97 percent ( $\triangle p_{i}=1-B R P$ price/ original price, Appendix Table A1). ${ }^{23}$ The book with the largest price decline, Saccardo's Sylloge fungorum, sold for an original price of $\$ 2,000(\$ 63,000$ in 2016) and for \$200 (\$5,420) under the BRP. Beilstein's (1918) Handbuch der Organischen Chemie sold for an original price of $\$ 2,000$ and for $\$ 400(\$ 10,840)$ under the BRP. Across disciplines, price declines were slightly smaller in chemistry ( 24.3 percent) than mathematics ( 27.4 percent).

\section{B. Swiss Books in Chemistry and Mathematics}

Our second identification strategy uses books that were published in Switzerland (and therefore not subject to the BRP) to control for unobservable factors that may have increased English-language citations to German-language books after 1942. To construct this control group, we collect all Swiss books in section 51 "Mathematik" and section 54 "Chemie" from the catalogs of the Swiss National Library. Founded in 1895, the Library's holdings include

\footnotetext{
${ }^{20}$ Most (323 of 334 BRP books) were published in German, and 5 were English-language translations. Prices declined less for these 5 books (by 16.9 percent), and citations increased more (from 0.388 to 0.838 per year). ${ }^{21}$ The 1909 Act offered 56 years (28 years initially plus the option to renew the copyright for another 28 years). One extremely old book, Pier Andrea Saccardo's (1881) Sylloge Fungorum presents a system for classifying mushrooms by spore color and form, which remained the standard until the field switched to analyzing DNA. 22 Thirteen of the remaining 15 books were published after 1941; these books were probably not available in the United States before the BRP.

${ }^{23}$ Prices declined for 242 of 271 BRP books with an original BRP price. Another 20 books experienced no change in price, and 9 chemistry books became more expensive under the BRP, by an average of 17.47 percent, increasing from an original price of $\$ 36.46$.
} 
1,683 books in chemistry that were published between 1921 and 1942, and 447 books in mathematics for the same year.

\section{Citations to BRP and Swiss Books, 1920-1970}

Our first measure for changes in follow-on science includes 9,841 citations to BRP books by new scientific articles and books between 1920 and 1970. Although scientific citations and patent citations are a standard-proxy for cumulative science and innovation (e.g., Waldinger 2010, Williams 2013), they are subject to bias and noise. We examine bias below and repeat our tests with alternative measures. There is also a substantial body of research, which documents the value of citations as a measure of follow-on innovation. Roach and Cohen (2012), for example, show that citations to scientific journal articles correspond closely to the research that mangers report using in their firms' R\&D.

To collect citations to BRP books and the control, we first search Google Scholar for the title (such as Die Chemie des Pyrrols) and author (such as "Fischer") of each BRP book. ${ }^{24}$ This search yields a total of 11,249 citations. Among 334 BRP books, 291 (87 percent) are cited at least once. Among 2,130 Swiss books, 486 books (23 percent) are cited at least once. Google Scholar searches "articles, theses, books, abstracts and court opinions from academic publishers, professional societies, online repositories, universities, and other web sites." ${ }^{25}$ It is currently the most complete source of citations to foreign language books (Meho and Yang 2007). ${ }^{26}$ Google's effectiveness may, however, vary across cohorts of publication years. To account for this issue, all regressions include control for the publication year of citing articles.

To measure the effect of the BRP conservatively, we only collected citations to the original German version of BRP books, excluding translations. Excluding translations estimates a lower bound of the effects of the BRP: Successful BRP books were more likely to be translated, and citations to the original declined when a translation became available because it was the closest (and for many US scientists preferable) substitute. For example, citations to Courant and Hilbert's (1931) Methoden der Mathematischen Physik declined

\footnotetext{
24 Fischer (1881-1945) received the Nobel Prize in chemistry for determining the structures of pigments in blood and bile as well as chlorophyll in leaves; these substances are derived from pyrrole.

${ }^{25}$ For books with multiple editions we collect citations to the edition whose publication year is closest to the publication year of the original book. Less than five percent of books have multiple editions in the same year; for these books we examine the edition with the largest number of citations.

${ }^{26}$ Meho and Yan (2007) compare citations to the work of 25 faculty members from three sources: the Institute for Scientific Information (ISI, or Web of Science), Scopus, and Google Scholars. Google Scholar has better coverage, but also requires substantially greater efforts of data collection (with a total of 3,000 hours compared with 1000 for the Web of Science and 200 for Scopus).
} 
after the publication of Methods of Mathematical Physics (vol. II, 1966). By 2016, the English version of Methods had received more than 16,000 citations.

A potential drawback of citations is that citations may be biased by unobservable changes in tastes. ${ }^{27}$ Paris et al. (1998) document a region-based bias in citations, and Jannot et al. (2013) show that scientists are more likely to cite statistically significant results. The most severe threat in our empirical setting is that US scholars may have withheld citations to German authors during the war and resumed citing German authors afterwards. For World War I, Iaria et al. (2016) show that US boycott of scientists from Central countries led to a decline in the transmission of knowledge, measured by new articles and Nobel-nominated work of scientists who had previously cited foreign or domestic research.

To examine the severity of bias during World War II, we analyze data on preferences for ethnically-themed goods, such as German foods and operas, and baby names with strong ethnic connotations. These measures document a strong and persistent change in ethnic preferences during World War I, but not for World War II. For example, the share of German-language operas dropped from 50 to 7 percent at the beginning of World War I, but declined only slightly in World War II (Appendix Figure A2, also Moser 2012b).

\section{Library Holdings of BRP and Swiss Books}

Historical library holdings are recorded in the National Union Catalog (NUC), pre1956 imprints, a "cumulative author list representing Library of Congress printed cards and titles reported by other libraries" (Mansell 1968-1981). To collect these data, we have accessed physical copies of the NUC at the Hoover Institution Library \& Archive. These records allow us to identify books that had entered at least one US library by 1956.

Among 291 BRP books with at least one citation, 283 are in the NUC, including 228 of 236 books in chemistry and all 55 books in mathematics. Among 486 Swiss books with at least one citation, 247 Swiss books are in the NUC, including 161 of 373 Swiss chemistry books and 86 of 113 Swiss math books. We examine the restricted data set of NUC books in the main specifications and use the full sample of 11,249 citations to 291 BRP and 486 Swiss books in robustness checks (e.g., Appendix Table A15).

\footnotetext{
${ }^{27}$ Citations may initially be biased against novel findings. For research published in the Web of Science, Wang et al (2016) show that articles which make more first-time ever combination across journals are less likely to be cited in the short run, but more likely to enter the top one percent of highly cited papers in the long run.
} 


\section{E. Citations from Publications in English and Other Languages}

To distinguish citations by authors who were differentially affected by the BRP, we identify the publication language of all citing publications. Among 9,053 citations to 283 BRP books between 1920 and 1970, 5,067 originate from English-language publications. Among 1,788 citations to 247 Swiss books, 1,014 originate from English-language publications. With 243 English-language citations, Courant and Hilbert's Methoden der Mathematischen Physik (1931) is the most cited book (Appendix Table A2).

To check whether English-language citations are a useful proxy for citations from US scholars, we collect data on publication cities for four highly cited books, including two BRP books (Alexandroff and Topf, 1935, Topologie and van der Warden, 1931, Moderne Algebra) and two Swiss books (Stiefel 1936, Mannigfaltigkeiten (Manifolds), and Leser 1939, Invariantentheorie Algebraische Formen). These data indicate that the large majority of English-language publications (73 percent) originate from the United States.

\section{F. Locations of Citing Authors and New PhDs}

To investigate the mechanism by which the BRP may have increased citations, we examine the geographic overlap between the locations of BRP books and the locations of citations. The ideal data for this test would measure the location of the citing author at the time of the citation. To approximate this information, we use the Mathematics Genealogy Project (MPG) to capture variation in the geographic locations of 1,812 authors who cite BRP books in mathematics. The MGP offers comprehensive coverage on advisors, advisees, and PhD-granting institutions for 196,303 mathematicians between 1666 and $2016 .{ }^{28}$

First, we use information on $\mathrm{PhD}$-granting institutions for professors and their advisees to identify the location of citing authors, as well as new $\mathrm{PhD}$ students in mathematics. Location data are available for all 1,995 citations by 1,812 authors to BRP books in mathematics. For example, David Gilbarg cites Courant and Hilbert's Methoden der Mathematischen Physik in his article on "Asymptotic Behavior and Uniqueness of Plane Subsonic Flows" in the Journal of Pure and Applied Mathematics in 1957. We assign this citation to Bloomington, Indiana because Gilbarg was an advisor to Norman Meyers, who graduated from Indiana University in 1957.

Then we identify BRP authors who were émigrés, using biographical data in the International Biographical Dictionary of Central European Émigrés (Strauss et al. 1983) and

\footnotetext{
${ }^{28}$ http://www.genealogy.ams.org/index.php, accessed January 28 to March 25, 2016.
} 
the Mathematics Genealogy Project. ${ }^{29}$ Our data include no books by émigré chemists and four books by five émigrés mathematicians, Richard Courant, Max Herzberger, John von Neumann, George Pólya, and Gabór Szego.

\section{G. US Patents that Build on Knowledge in BRP Books}

As an alternative measure for cumulative innovation, we examine changes in the number of US patents that use knowledge from BRP books. To construct this measure, we search the text of US patents between 1920 and 1970 for sections that cite BRP books as relevant scientific knowledge. ${ }^{30}$ For example,

United States Patent 3,210,370 for a "PROCESS FOR PREPARING 2,2'-METHYLENEBISARENEIMIDAZOLES" filed on June 22, 1964, issued to Joseph J. Ursprung, Portage, Michigan. and assigned to The Upjohn Company, in Kalamazoo, Michigan,

uses Beilstein's Handbuch der Organischen Chemie to illustrate the products of its invention:

“ETHYL 2- (5,G-DEIMEEFIHYL-ZBE'NZHHDAZOLYL) ACETATE A mixture of $6.8 \mathrm{~g}$. (0.05 mole) of 4,5-dimethyl-1,2- phenylenediamine (Beilsteins Handbuch der Organischen Chemie, 13, 179 4th edition, 1930)" and

“5,5,6-TRIMETHYL-2,2-METHYLENEBIS- BENZIMIDAZOLE A mixture of $4.64 \mathrm{~g}$. (0.02 mole) of ethyl 2-(5,6-dimethyl-Z-benzimidazolylacetate (prepared as described above), 2.44 g. of 4-methyl-1,2-phenylenediamine (Beilsteins Handbuch der Organischen Chemie, 13, 148, 4th edition, 1930), and $50 \mathrm{ml}$. of 1,2,4-trichlorobenzene was stirred and heated to $180 \mathrm{C}$.

Between 1920 and 1970, 238 US patents include at least one citation to a BRP book.

\section{H. Research Fields of BRP and Swiss Books}

To control for variation in citations across research fields, we match the classification of research topics in the reports of the US Alien Property Custodian (1944) with the classification of topics in the Swiss National Library. The Custodian (1944) assigns 228 chemistry books to 38 topics, such as "catalysis," and 55 mathematics books to 14 topics, such as "non-Euclidean geometry." The Swiss National Library distinguishes 128 topics within chemistry and 28 topics within mathematics. We match these two systems to create 25 mutually exclusive research fields within chemistry and 8 within mathematics.

\footnotetext{
${ }^{29}$ Four of five émigrés from Straus (1983) appear as an advisor of at least one US PhD student in the MGP after 1932. Max Herzberger (who is only listed in Straus) worked in the private sector, and did not advise students. ${ }^{30}$ We perform an automatic search of the full text of patents in the USPTO Bulk Data Downloads: Patent OCR Text (available at www.google.com/patents) for authors and titles, and then hand-check all potential matches.
} 
For BRP books in chemistry, compounds are the most common research field, followed by organic chemistry and metals (Appendix Table A4). In mathematics, general mathematics and geometry are the most common research field. In each of these fields prices decline after 1942, and citations to BRP books increase (Appendix Table A4).

\section{EFFECTS OF THE BRP ON CITATIONS}

To investigate the effects of the BRP, we pursue two complementary identification strategies. The first strategy minimizes selection by comparing changes in citations to the same BRP book from English-language and other authors. The second strategy addresses the potential issue that citations by English-language authors may have increased independently of the BRP. It compares changes in citations by English-language authors to BRP books and Swiss books, which were not eligible for the BRP due to Switzerland's neutrality.

\section{A. Comparing Citations to the same BRP Book by English-language and Other Authors}

Counts of new publications that cite BRP books in English and other languages are similar in levels and trend before the BRP (Figure 1); 0.26 publications in English and 0.30 publications in other languages cite the average BRP book per year until 1941 (Appendix Table A5). Afterwards, English-language publications increase to 0.566 per year, a 118 percent increase from pre-BRP levels. At the same time, citations to the same books by authors writing in other languages only increase to 0.391, a 30 percent increase (Appendix Table A5). ${ }^{31}$ This differential increase is particularly remarkable given that many US scientists continued to publish in German until the late 1960s (e.g. Ammon 2001, p. 465), so that their papers would be captured in the control group even if they used BRP books. Notably, citations to the original German version of individual BRP books (such as Methoden der Mathematischen Physik, Appendix Figure A3) decline after the introduction of Englishlanguage translations, which are the closest substitutes to BRP books.

To estimate the effects of the BRP, we first estimate OLS regressions:

$$
\text { cites }_{\text {ilt }}=\alpha \text { English }_{l}+\beta \text { English }_{l} \times \text { post }_{t}+\text { book }_{i}+\tau_{t}+\varepsilon_{\text {ilt }}
$$

where the dependent variable cites $_{\text {ilt }}$ measures citations to book $i$ in language $l$ (English vs. other languages) and year $t$. The variable $E_{n g l i s h}$ indicates new scientific publications in English that cite BRP books and post $_{t}$ indicates years after 1941. The control group are citations to the same BRP book by authors writing in other languages. A vector of book fixed

\footnotetext{
${ }^{31}$ Including 8 BRP books not in the NUC, English-language citations increase by 117 percent from 0.256 to 0.557 , and citations from other languages increase by 31 percent from 0.294 to 0.386 .
} 
effects controls for book-specific differences in levels of citations across books. Citation year fixed effects $\tau_{t}$ control for variation in scientific output over time, e.g., as a result of variation in funding for research.

The identifying assumption of this basic regression is that changes in Englishlanguage and other citations to BRP books would have been similar in the absence of the BRP. Comparisons of English-language and other citations show that trends in Englishlanguage and other citations were nearly identical until 1942 (Figure 1), supporting the identifying assumption. Then, the coefficient $\beta$ estimates the effect of the BRP.

OLS estimates indicate that citations to BRP books increased by an additional 0.211 per book and year after 1941 compared with citations from other languages (Table 1, column 1, significant at 1 percent). Relative to a pre-BRP average of 0.263 English-language citations for BRP books, this implies an 80 percent increase. Regressions with controls for research fields and the publication years of BRP books yield an estimate of 0.229 (Table 1, column 3 , significant at 1 percent), which implies an 87 percent increase.

\section{B. Time-varying Estimates for English-language and Other Authors}

Estimates of time-varying effects indicate no significant differences in citations before the BRP, confirming visuals of the raw data in Figure 1. Until 1941, estimates range from 0.179 in 1933-34 (p-value 0.04, Figure 2) to 0.065 in 1941-42 (p-value 0.23). In the final years of the war, estimates decline to -0.051 (1943-44, p-value 0.17).

Time-varying estimates increase and become significant in 1947, with an estimate of 0.200 in $1947-48$ (p-value 0.00) and 0.210 in 1953-54 (p-value 0.03). They remain large and statistically significant until the final period of our sample in 1969-70, with 0.412 additional citations (p-value 0.00). Compared with a pre-BRP mean of 0.263 , this implies a 157 percent increase in English-language citations to BRP books.

\section{B. Further Checks of the Identifying Assumption}

A potential challenge to the identifying assumption is that scientific output varies across research fields and over time. For example, research output may vary due to variation in funding (e.g. Tabacovic and Wollmann 2016) or as a result of scientific breakthroughs, independently of the BRP. If such changes favor English-language publications in BRP fields after 1941, then the basic difference-in-differences test overstates the effect of the BRP.

To address this issue, we re-estimate the baseline regressions with fixed effects for the fields and citation years of BRP books. These tests confirm the main results: English- 
language publications increase by an additional 0.229 per book and year (Table 1, column 2, significant at 1 percent), which implies an 85 percent increase. In alternative specifications with a linear pre-trend for English-language publications, the trend is not statistically significant (with a p-value of 0.24), but the estimated effect of the BRP is large, at 0.448 (Appendix Table A6, column 1, significant at 10 percent).

Even though OLS is our preferred model for the linear difference-in-difference specifications, we estimate robustness checks with a non-linear quasi-maximum likelihood (QML) Poisson model to address the count data nature of citations. ${ }^{32}$ QML Poisson estimates confirm the main results, with a 0.497 increase in the growth rate of new citations by English-language authors (Table 1, column 4 , significant at 1 percent). ${ }^{33}$

\section{Changes in English-language Citations to BRP and Swiss}

Even though pre-trends in citations were comparable, some of the increase in citations by English-language authors after 1942 may have been due to unobservable factors that increased the research output of US scholars after World War II, relative to authors publishing in other languages. Tabakovic and Wollmann (2016), for example, show that both the number and the quality of scientific publications increase in response to exogenous increases in research funding as a result of football wins. In the post-war United States, geopolitically motivated investments in science may have led to an increase in Englishlanguage publications, mechanically increasing English-language citations.

To address this issue, we compare changes in citations by English-language authors to BRP books with changes in citations by English-language authors to Swiss books. Like German chemists and mathematicians, Swiss scientists - such as Alexander Ostrowski (18931986) and Eduard L. Stiefel (1909-1978) - were leaders in their fields, and they published primarily in German. ${ }^{34}$ Unlike German-owned books, however, books with Swiss-owned copyrights were not eligible for the BRP due to Switzerland's neutrality during the war.

Compared with our first identification strategy, this second approach is more affected by selection. Archival records for J.W. Edwards explain that "Edwards Brothers' editor,

\footnotetext{
${ }^{32}$ Among 19,680 year-book-language pairs of the dependent variable, 15,504 (78 percent) take a value of zero.

${ }^{33} \mathrm{We}$ also re-estimate the main specifications with the logarithm of citations as the dependent variable, adding a small number (0.00005) to the count of citations. Log regressions confirm the main results, with a 65 percent increase in English-language citations for BRP books.

${ }^{34}$ Stiefel's (1935) dissertation Richtungsfelder und Fernparallelismus in n-dimensionalen Mannigfaltigkeiten describes n-dimensional (Stiefel) manifolds $V_{k}\left(\mathrm{R}^{n}\right)$, or the set of all orthonormal $k$-frames in $\mathrm{R}^{n}$. Stiefel was a co-inventor of the conjugate gradient method and the study of characteristic classes. He founded the Swiss Institute of Applied Mathematics, whose objective was to design and construct an electronic computer.
} 
Bernard A Uhlendorf (formerly employed by the University of Michigan Library) was responsible for choosing the titles appropriate for EB's publication program" (Bokas and Edwards 2011, p. 25). These records alone, however, are not sufficient to evaluate selection. BRP books may be positively selected if publishers chose books with high expected demand. Or they may be negatively selected because US publishers had not considered it worthwhile to publish these books under the market price for copyrights.

Book fixed effects help to address the selection issue by controlling for variation in the level of citations across books. To minimize differences in the trend of citations, we use a Mahalanobis propensity score matching approach (Abadie and Imbens 2002) to create a matched sample of comparable Swiss and BRP books. This process creates a sample of BRP and Swiss book that cover similar research fields and have comparable pre-BRP stocks of citations (using citations by non-English-language authors, Appendix Table A8).

In the matched sample, Swiss books receive fewer citations overall, but trends in citations are comparable until 1942 (Figure 3). ${ }^{35}$ After the war, citations to BRP books grow to 0.360 in 1946 and 0.888 in 1956 , while citations to Swiss books increase much less.

Citations to BRP books remain high around 0.800 per book year until 1970, while citations to Swiss books remain below 0.400 .

To investigate this differential change, we estimate OLS regressions with controls for book fixed effects and for the publication years of citing publications:

$$
\text { cite }_{i t}=\beta \text { BRP }_{i} * \text { post }_{t}+\text { book }_{i}+\tau_{t}+\varepsilon_{i t}
$$

where the dependent variable cite $_{i t}$ measures citations to BRP and Swiss books by new English-language publications to book $i$ per year $t$ between 1920 and 1970, and the indicator variable $B R P$ equals 1 for books that US publishers reprinted under BRP.

OLS estimates show that an additional 0.386 new publications by English-language authors per year cite BRP book after 1941 compared with Swiss books (Table 2, column 1, significant at 1 percent). Relative to a pre-BRP mean of 0.283 , this implies a 136 percent increase. To control flexibly for idiosyncratic variation in the productivity of research fields, we estimate regressions with an interaction for fields * citation year fixed effects. These estimates suggest that English-language citations increased by an additional 0.438 citations

\footnotetext{
${ }^{35}$ Between 1941 and 1945, when the Allied bombing campaign destroyed research facilities in Germany, citations to BRP books declined more than citations to Swiss books. Bombings reached a peak of 130 tons per months at the beginning of 1945 (Webster and Frankland 1961, Annex). Waldinger (2016) estimates that a 10 percent increase in the destruction of physical capital reduced research output by 0.05 standard deviations.
} 
per year for BPR books (Table 2, column 3, significant at 1 percent), which implies a 155 percent increase. $^{36}$

\section{Time-varying Estimates for BRP and Swiss Books}

Time-varying estimates indicate no significant differences in citations before the BRP, and they show a large increase in citations after the war. Until 1941, estimates are not significant and range from -0.075 in 1931-32 (p-value 0.64, Figure 4) to 0.137 in 1941-42 (pvalue 0.17$)$. In the final years of the war, estimates decline to 0.075 (1943-44, p-value 0.48$)$.

After 1945, estimates increase to 0.291 in $1947-48$ (p-value 0.01) and 0.596 in 195456 (p-value 0.00). Time-varying estimates remain large and significant until the final period in 1969-70, with 0.482 additional citations (p-value 0.00). Compared with a pre-BRP mean of 0.283 , this implies a 170 percent increase (Figure 4).

\section{Combining the Two Identification Strategies}

We now combine the two identification strategies, by comparing the differential change in citations to BRP books from English-language and other authors with the same differential change for Swiss books. Triple-differences OLS regressions estimate:

$$
\begin{gathered}
\text { cite }_{\text {ilt }}=\beta_{1} \text { English }_{l}+\beta_{2} \text { English }_{l} * \text { BRP }+\beta_{3} \text { English }_{l} * \text { post }_{t}+\beta_{4} \text { BRP }_{i} * \text { post }_{t}+ \\
\beta_{5} \text { English }_{l} * B R P_{i} * \text { post }_{t}+\text { book }_{i}+\tau_{t}+\varepsilon_{i l t}
\end{gathered}
$$

In this specification, the coefficient $\beta_{5}$ captures the differential increase in citations from English-language authors compared with other authors, for citations to BRP books compared with Swiss books. Estimates of $\beta_{5}$ for the matched sample indicate that BRP books receive 0.202 additional English-language citations per year compared with Swiss books. Compared with an average of 0.3000 English-language citations per year for BRP books until 1941, this implies a 67 percent increase (Table 3, column 1, significant at 5 percent). Estimates are robust to controlling flexibly for variation in the productivity of research fields, by including interactions between research fields and citation year fixed effects (Table 3 column 2, significant at 1 percent).

\section{MeChanism: Reductions In PRICE}

A key benefit of the empirical setting is that prices are observable under different copyright regimes for the same book, in the same year, when knowledge in the book is still

\footnotetext{
${ }^{36}$ Estimates for all 293 BRP books and 247 Swiss books show 0.392 additional new articles or books cite BRP books after 1941 (Appendix Table A9). An additional test restricts the sample to books in the Library of Congress; estimates are robust (Appendix Table A11).
} 
relevant and new. Consistent with earlier research on book prices (Li et al forthcoming), prices decline when copyrights are weakened, with an average reduction of 25 percent. We exploit this change to examine the effects of price on cumulative science.

\section{A. Effects of Price}

Predictions from a purposefully straightforward model of cumulative knowledge guide the empirical analysis. Suppose two identical generations of researchers produce new knowledge in periods $t-1$ and $t$. The concept of cumulative science (Scotchmer 1991) is captured by allowing second-generation scientists in period $t$ to build on knowledge $y_{t-1}$ created by researchers in the first generation $t-1$. Normalizing the price of new knowledge $y_{t}$ to equal 1 , scientists receive a sure payoff $y_{t}$ if they produce new knowledge; this payoff can take the form of a money, peer recognition, or any other rewards that scientists value.

To access existing knowledge $y_{t-1}$, second-generation scientists pay a price $p$. In our setting, $p$ represents the price of a book, but $p$ could also be an access fee for a medical resource center (as in Furman and Stern 2012), or an online depository of scientific articles. To reflect the indivisibility of existing knowledge, we assume that scientists pay $p$ to use any quantity of existing knowledge. In other words, scientists must buy the entire book, or pay the full fee to access any part of the collection.

In addition to existing knowledge $y_{t-1}$, scientists use capital $k_{t}$, which is available at the rental rate $r$. Unlike existing knowledge, capital is divisible. Scientists are price takers for $p$ and $r$. Depending on input prices $p$ and $r$, scientists either invest in follow-on science, and receive $y_{t}=f\left(y_{t-1}, k_{t}\right)$, or they do nothing, and receive a payoff of zero.

Second-generation scientists choose $k_{t}^{*}$ to maximize net payoffs $y_{t}-p-r k_{t}{ }^{*}$. They invest in creating new knowledge only if $p$ is below a threshold price $p$ ' such that

$$
f\left(y_{t-1}, k_{t}^{*}\right)-p^{\prime}-r k_{t}^{*} \geqslant 0 \text { or } p^{\prime}=f\left(y_{t-1}, k_{t}^{*}\right)-r k_{t}^{*}
$$

This implies - under a general set of production functions - that scientists produce more new knowledge when $p$ is low. For a Cobb-Douglas production function $y_{t}=y_{t-1}{ }^{1-\alpha} k_{t}^{\alpha}$, the threshold price equals

$$
p^{\prime}=\alpha^{\alpha / 1-\alpha}(1-\alpha) y_{t-1} r^{-\alpha / 1-\alpha}
$$

To empirically examine how changes in price influence the creation of new science, we re-estimate the baseline equation (1) with an interaction term for changes in price: cites $_{i l t}=\alpha$ English $_{l}+\beta$ English $_{l} \times$ post $_{t}+\theta \Delta p_{i} *$ English $_{l} *$ post $_{t}+$ book $_{i}+\tau_{t}+\varepsilon_{i l t}$ 
where $\Delta p_{i}$ measures the difference between the original price and the republication (BRP) price for BRP book $i$ normalized by the original price.

OLS estimates of equation (5) show that a 10 percent decline in price is associated with 0.119 additional citations (Table 4, column 2, significant at 1 percent). Compared with a pre-BRP mean of 0.264 annual citations for BRP books, this implies a 45 percent increase. ${ }^{37}$

\section{B. Substitutes for BRP Books}

A potential concern for estimating the effect of a decline in price is that we cannot observe the process by which publishers set the price for BRP books. To investigate this issue, we check whether price declined more for books with more pre-BRP citations by non-English publications. This correlation is small and not statistically significant (Appendix Figure A4).

A related concern is that we cannot measure cross-price elasticities across books, and that US publishers may have lowered prices more for books with close substitutes. If there was unobservable variation in the price setting behavior of publishers, substitution effects would cause the estimate of $\theta$ to be downward biased, as long as books with close substitutes experienced a smaller increase in citations.

Historical records in the correspondence of the American Library Association suggest that, at a time when German scientists were still at the forefront of mathematics and many field of chemistry, few substitutes existed for access to German science. BRP books, such as Alexandroff and Hopf's Topology, Courant and Hilbert's Methods of Mathematical Physics, or Beilstein's Handbook of Organic Chemistry, were first to summarize the current state of science in new fields of mathematics and chemistry (Richards 1981, p. 254).

Ideally, we would estimate cross price elasticities for BRP books and potential substitutes, but this is not possible due to data constraints. ${ }^{38}$ Instead, we use Amazon's sales algorithm to identify books that customers who bought BRP books "also bought" or "frequently bought together" with the four most highly cited BRP books in mathematics as a proxy for related books. ${ }^{39}$ We then collect the year of the first edition of all of these related books to check whether they may have been available in the United States before 1942.

These data show that most of the books that are thematically related to BRP books were first published after 1942 (Appendix Figure A5). We also examine data on citations to

\footnotetext{
${ }^{37}$ With a separate linear pre-trend for English-language citations, the estimate is 0.119 (significant at 1 percent, Appendix Table A6, column 2).

${ }^{38}$ Greer et al. (2006) estimate cross-price elasticities to quantify the effects of an increase in the price of a drug due to patent protection - on the demand for quinolones by other firms that use the same molecule.

${ }^{39}$ Data collected from www.amazon.com, accessed September 19-30, 2016.
} 
these books in newly issued US patents per year (described in more detail below). This test confirms that there were no good substitutes for BRP books before the BRP. None of the potential substitutes for BRP books was cited in a US patents until 1957.

The closest substitute for a BRP book was the English translation of the same book. Translations began to appear in the 1960s, when English replaced German as the lingua franca of science. With the publications of a translation, citations to the original BRP book declined. For example, citations to Courant and Hilbert's Methoden der Mathematischen Physik slowed dramatically when translations hit the market (Appendix Figure A3). By excluding citations to these translations, we estimate a lower bound for the effects of the BRP.

\section{Time-Varying Effects of Price on English-Language Citations}

To investigate the timing of changes in citations, we estimate $B R P * \Delta p_{i} *$ post separately for two-year intervals between 1930 and 1970:

cites $_{i l t}=\alpha$ English $_{l}+\beta$ English $_{l} \times$ post $_{t}+\Sigma_{s} \theta_{s} \Delta p_{i} *$ English $_{l} * \eta_{s}+$ book $_{i}+\tau_{t}+\varepsilon_{i l t}$

where the indicator variable $\tau_{t}$ denotes two-year intervals $1930-31,1932-1933, \ldots$ to $1969-70$, and years between 1920 and 1929 are the excluded period.

Time-varying estimates indicate no significant differences in citations before the BRP, and show a large increase in citations after the war (Figure 5). Until 1941, estimates range from -0.025 in 1931-32 (p-value 0.20) to 0.041 in 1941-42 (p-value 0.04). After 1945, estimates increase to 0.102 in 1947-48 (p-value 0.00) and 0.153 in 1953-54 (p-value 0.00). Estimates remain large and significant until 1969-70, with 0.180 additional citations (p-value 0.00). Compared with a pre-BRP mean of 0.263 , this implies a 68 percent increase.

\section{BRP vs Swiss Books}

In Table 5 we re-estimate the effects of a decline in price using our second identification strategy, which compares English-language citations to BRP and Swiss books. OLS estimates for the matched sample of BRP and Swiss books show that a 10-percent decline in price is associated with 0.116 additional citations per year (Table 6, column 1 , significant at 1 percent). Compared with an average of 0.284 citations in the matched sample until 1942, this implies an increase of 41 percent. ${ }^{40}$ Year-specific estimates indicate no significant differences in citations before the BRP, and they show a large increase in citations after the war (Figure 6). Combining the two identification strategies indicates that the same

\footnotetext{
${ }^{40}$ Results on the full sample of BRP and Swiss books indicate that a 10 percent decline in price is associated with 0.101 additional citations per year, or 38 percent (Appendix Table A9, column 1, significant at 1 percent).
} 
decline in price is associated with 0.128 additional English-language citations, compared with other-language citations to BRP books compared with Swiss books (Table 6, column 1, significant at 1 percent).

\section{E. Heterogeneous Effects across Disciplines}

Next, we extend the knowledge production function to allow for heterogeneous effects across disciplines. Suppose $y_{c, t}=z\left(y_{c, t-1}, k_{t}\right)$ represents chemistry, or another discipline, in which knowledge production requires physical capital (such as laboratory space), and $y_{m, t}$ $=g\left(y_{m, t-1}, k_{t}\right)$ denotes mathematics, or another discipline in which knowledge creation depends primarily on human capital. Let the elasticity of knowledge production with respect to physical capital be $e^{c}\left(y_{c, t-1}, k_{t}\right)=z_{k}\left(y_{c, t-1}, k_{t}\right) k_{t} / \mathrm{z}\left(y_{c, t-1}, k_{t}\right)$ for chemistry and $e^{m}\left(y_{c, t-1}, k_{t}\right)=g_{k}\left(y_{m, t-}\right.$ $\left.{ }_{1}, k_{t}\right) k_{t} / \mathrm{g}\left(y_{m, t-1}, k_{t}\right)$ for mathematics, and suppose $e^{m}\left(y_{m, t-1}, k_{t}\right)<e^{c}\left(y_{c, t-1}, k_{t}\right)$ for every $\left\{y_{m, t-1}, y_{c, t-1}\right.$, $\left.k_{t}\right\}$. Then discipline-specific threshold prices are

$$
\begin{gathered}
p_{c}{ }^{\prime}=z\left(y_{c, t-1}, k_{c}{ }^{*}\right)-z_{k}\left(y_{c, t-1}, k_{c}{ }^{*}\right) k_{c}{ }^{*}=z\left(y_{c, t-1}, k_{c}{ }^{*}\right)\left(1-e^{c}\left(y_{c, t-1}, k_{c}{ }^{*}\right)\right) \\
p_{m}{ }^{\prime}=g\left(y_{m, t-1} k_{m}{ }^{*}\right)-g_{k}\left(y_{m, t-1}, k_{m}{ }^{*}\right) k_{m}{ }^{*}=g\left(y_{m, t-1} k_{m}{ }^{*}\right)\left(1-e^{m}\left(y_{m, t-1}, k_{m}{ }^{*}\right)\right)
\end{gathered}
$$

If existing knowledge is equally valuable across disciplines, so that $y_{c, t-1}=y_{m, t-1}$, then $p_{m}{ }^{\prime} \geq p_{c}{ }^{\prime}$. More generally, $p$ ' is weakly decreasing in the elasticity of knowledge with respect to physical capital:

$$
\frac{\mathrm{d} \mathrm{p}^{\prime}}{\operatorname{de}\left(y_{t-1}, k *\right)}=-\mathrm{f}\left(y_{t-1}, k *\right) \leq 0 \text { if } \mathrm{f}\left(y_{t-1}, k *\right) \geq 0
$$

For a Cobb-Douglas production function $y_{t}=y_{t-1}{ }^{1-\alpha} k_{t}^{\alpha}$, where $\alpha$ is the elasticity of knowledge production with respect to physical capital,

$$
\frac{\mathrm{d} \mathrm{\textrm {p } ^ { \prime }}}{\mathrm{d} \alpha}=\alpha^{\frac{\alpha}{1-\alpha}} \text { y } r^{\frac{\alpha}{\alpha-1}} \frac{1}{1-\alpha} \log (\alpha / r) \leq 0 \text { if } \alpha \leq r
$$

which implies that the threshold price of existing knowledge at which scientists invest in new knowledge is (weakly) increasing in the elasticity of knowledge with respect to capital.

Confirming these predictions, plots of citations suggest stronger effects on citations in mathematics than chemistry. English-language citations to BRP books in mathematics increased from 0.198 per book and year before 1942 to 0.472 in 1946 and 1.890 in 1956, while citations in other languages remained low (Figure 8). English-language citations to BRP books in chemistry increased from 0.244 per book and year before 1942 to 0.469 in 1956, while other citations stay roughly constant (Appendix Figure A6).

To test for heterogeneous effects across disciplines, we estimate

$$
\text { cites }_{i l t}=\alpha \text { English }_{l}+\beta \text { English }_{l} \times \text { post }_{t}+\varphi \text { English }_{l} * \text { math }_{i} * \text { post }_{t}+\text { book }_{i}+\tau_{t}+\varepsilon_{i l t}
$$


where math $_{i}$ is an indicator for BRP books in mathematics. Estimates for English * math * post indicate that English-language citations to BRP in mathematics increase by an additional 0.674 compared with chemistry and citations in other languages after 1941 (Table 7, column 1, significant at 5 percent). Relative to a pre-BRP mean of 0.263 citations, this implies an additional 2.6-fold increase. Estimates with flexible controls for idiosyncratic variation in research output over time and across fields yield 0.565 additional citations, which implies an additional 2.2-fold increase for mathematics (Table 7, column 2, significant at 5 percent, with interaction terms fields * citation years). ${ }^{41}$ Intensity regressions imply that a 10 percent decline in price is associated with 0.238 additional English-language publications for mathematics (English * math $* \Delta p *$ post, Table 7, column 4, significant at 1 percent) ${ }^{42}$ Relative to a pre-BRP mean of 0.263 for BRP books, this implies a 90 percent increase.

Time-varying estimates of a decline in price indicate no significant differences in English-language citations to BRP math books compared with other citations before 1942 . Until 1941 estimates range from -0.051 citations in 1931-32 (p-value 0.03, Figure 8) to 0.066 in 1935-36 (p-value 0.07). After the war, estimates increase to 0.309 for 1951-52 (p-value 0.05 , Figure 8), and 0.447 in 1953-54 (p-value 0.00). Estimates remain large and significant until 1969-70, with 0.438 (p-value 0.00 ), implying a 166 percent increase. ${ }^{43}$

\section{F. Books by Émigré Scientists}

Previous research has shown that research fields in which the United States received a German Jewish émigré chemist after 1932 experienced a 31 percent increase in patenting by US inventors compared with the research fields of other German chemists (Moser et al. 2014). Similarly, the arrival of émigrés may have amplified the effects of their books on science and innovation in the United States. Five authors of BRP books in mathematics moved to the United States after 1942 (Appendix Table A12): Richard Courant (1888-1972), Max Herzberger (1899-1982), John von Neumann (1883-1953), George Pólya (1887-1985), and Gábor Szegő (1895-1985).

Plots of citations show that books by these five émigrés experienced a larger increase in citations after 1941 compared with other BRP books. The average émigré book received

\footnotetext{
${ }^{41}$ Controlling for a linear pre-trend leaves the estimate for English * math * post unchanged at 0.674 (Appendix Table A6, column 3, significant at 5 percent), and increases English * post to 0.317 (p-value 0.18).

${ }^{42}$ For each 10 percent decline in price, BRP math books receive 0.303 additional English-language citations after $1941\left(\right.$ English $_{l} * \Delta p_{i} *$ post $_{t}+$ English $_{l} *$ math $_{i} * \Delta p_{i} *$ post $_{t}$, significant at 10 percent, Table 7, column 4).

${ }^{43}$ For chemistry, estimates of time-varying effects range from -0.019 in 1933-34 (with a p-value of 0.47 ) to 0.038 in 1941-42. After 1941, estimates reach 0.066 in 1947-48 (p-value of 0.02), 0.068 in 1953-54 (p-value of 0.04 ), and remain large and significant until 1969-1970 with an estimate of 0.104 (p-value of 0.19).
} 
0.500 citations in 1934, and 0.750 citations in 1940 and 1941. Citations increase after 1941 to 3.250 in 1953 and remain high, with 3.500 citations in 1970 (Figure 9).

Importantly, however, our results are robust to excluding books by émigré authors. Citations per book and year to non-émigré BRP books increased from 0.350 per book in 1934, 0.325 in 1940 and 0.689 in 1941, to 2 in 1953, and remained at this level until 1965 (Figure 9). ${ }^{44}$ We also re-estimate the baseline specification for mathematics with an additional interaction term for books by émigrés. These estimates confirm that the effects of the BRP were not driven by the émigrés. Controlling for émigrés leaves the estimate for BRP * post at 0.479 (Appendix Table A13, column 1, significant at 10 percent).

\section{DIFFUSION ACROSS US LIBRARIES}

A potential mechanism by which lower book prices can encourage the creation of new science is by enabling more libraries to buy a book and grant access to researchers near that library. To investigate this mechanism, we examine historical data on library holdings, scientists' loans of library books, and changes in the locations of citing authors.

\section{A. Variation in Library Holdings}

Data on historical library holdings, which we construct from the National Union Catalog (NUC, Mansell 1968-1981), indicate that BRP books had reached libraries outside academic centers of the American Northeast and Chicago (Figure 10). By 1956, university libraries, like Ohio State, Oregon, and the University of Virginia held a substantial number of BRP books. By comparison, Swiss books remained concentrated in the holdings of two wealthy research libraries, the John Crerar Research Library at Chicago and Yale.

Library data also show that BRP books whose price declined more in 1942 had become more widely available across US libraries by 1956. BRP books in the top quartile of the price decline (ranging from 40 to 90 percent) had entered the holdings of 20 libraries and 11 US states by 1956 (Appendix Figure A8). For example, Beilstein's Handbuch der Organischen Chemie (1918), with a price decline of 90 percent, was available in 90 of 218

\footnotetext{
${ }^{44} \mathrm{We}$ also re-estimate the baseline specification for mathematics with an additional interaction term for books by émigrés. These estimates confirm that the effects of the BRP were not driven by the émigrés. Controlling for émigrés leaves the estimate for $B R P *$ post at 0.479 (Appendix Table A13, column 1, significant at 10 percent).
} 
US libraries. By comparison, BRP book in the bottom quartile of the price decline ( 8 percent or less) were only accessible in 14 of 218 US libraries. ${ }^{45}$

\section{B. Loans of BRP Books}

Despite the richness of the data, the NUC alone cannot capture changes in the usage of BRP books over time. ${ }^{46}$ To address this issue, we examine physical copies of check-out sheets that are attached to the inside back cover of a each book. We were able to collect these data for 127 books, 45 percent of all BRP books in the Stanford University library in $2016 .{ }^{47}$

These data reveal a striking overlap between changes in the use and changes in citations (Figure 11). Until 1941, only two BRP books had been borrowed from the Stanford library at least once (Stereochemie by K. Freudenberg and Die Mathematischen Hilfsmittel des Physikers by E. Madelund). After 1941, three additional BRP books were borrowed for the first time in 1944, two in 1945, 1948, 1949, and 1952 each, and five in 1955. Data on the overall use of books (shown as the dashed line in Figure 11) further indicate that scientists used BRP books repeatedly in the 1940s and 50s.

\section{Citing Authors Near BRP Books}

Next, we perform a geographic analysis of citations to test whether authors who were near BRP books added more citations to BRP books after 1942 compared with authors in more distant locations. Plots of location data already show that citations tracked the geographic diffusion of BRP books (Figure 12). Before 1942, 64 percent of citations to BRP books originate from the US Northeast (around Cambridge MA, Princeton, and Providence) and from Chicago. Afterwards, citations expand to the Western and Southern United States.

To test whether authors near BRP books became more likely to use BRP books after 1942, we estimate:

$$
\text { cite }_{k t}=\beta \text { within } 25 \text { miles }_{k} \times \text { post }_{t}+\eta_{k}+\tau_{t}+\varepsilon_{k t}
$$

\footnotetext{
${ }^{45}$ Each additional 10 percent decline in price was associated with a 1.3 percent increase in the share of libraries that held a BRP book (with a p-value of 0.00, Appendix Figure A8). Excluding outliers (such as Beilstein), which can be found in more than 40 percent of US libraries, leaves the estimate at 0.8 (with a p-value of 0.00 ). ${ }^{46}$ Libraries did not systematically record acquisition dates for science books. For example, we received the following response from a Curator of Special Collections at Stanford's Library: "The library did not maintain any acquisition records before 1994 for this type of materials. I asked our acquisitions department if there is any way to capture this information, but it appears unlikely. This type of information simply was not considered useful for these books" (Kathleen M. Smith, Stanford, April 4, 2016).

${ }^{47}$ The average BRP book in Stanford's library sold for $\$ 68.16$ until 1941, and became 34 percent cheaper under the BRP. Loan data exclude reference works, such as Beilstein, because they cannot be borrowed. We are less likely to observe the original cards for popular books because check-out sheets were replaced once they had filled up; this lead us to estimate usage with a delay for more popular books.
} 
where the dependent variable cite $_{k t}$ counts citations from authors at location $k$ and year $t$. The explanatory variable within 25 miles $_{k}$ indicates locations within a 25-mile radius of a BRP book; 87 of 101 locations are within a 25-miles of BRP books. To control for locationspecific differences in citations (e.g., due to variation in research funding), the vector $\eta_{k}$ includes location fixed effects.

OLS estimates confirm that locations near BRP books experienced a larger increase in citations. Authors within 25 miles of BRP books produce an additional 0.184 publications that cite BRP books per year after 1941(Appendix Table A14, column 1, significant at 1 percent) compared with authors in more distant locations. Relative to a pre-BRP mean of 0.031 , this implies a 5.9-fold increase.

Importantly, there is no evidence of differences in the trends of citations before 1941, even though levels of citations are lower in more distant locations (Appendix Figure A9). The estimated effects of nearness also attenuate with distance and eventually become negative. Locations within a 50-mile radius produce 0.138 additional citations (Appendix Table A14, column 2, significant at 1 percent), which implies a 4.5-fold increase. With a full set of distance dummies, coefficients for locations within 25 miles and 25-50 miles are positive, large, and statistically significant (at the 1 percent level, Appendix Table A14, column 4), whereas estimates become negative or insignificant above 50 miles.

\section{Alternative Measures: New PhDs And Patents}

Although citations are the standard measure of knowledge flows and cumulative innovation (e.g., Eysenbach 2006; Furman and Stern 2012), they are imperfect (e.g. Paris et al. 1998; Jannot et al. 2013). To address this issue, we present additional evidence from two complementary measures for cumulative science and innovation: new PhDs in mathematics and new US patents that build on knowledge in BRP books.

\section{A. New PhDs in Mathematics}

Changes in the number of new PhDs are a useful complement to book-specific changes in citations, because they capture variation in scientific output above the level of individual BRP books. This helps address the issue that the availability of translations or other types of substitutes may have influenced citations to BRP books.

To construct this measure, we examine data on 13,623 mathematicians who received their PhDs between 1920 and 1970 across 180 locations from the Mathematics Genealogy Project. We then re-estimate the distance regressions in equation (9) for PhDs: 


$$
P h D_{k t}=\beta \text { within } 25 \text { miles }_{k} \times \text { post }_{t}+\eta_{k}+\tau_{t}+\varepsilon_{i t}
$$

where $P h D_{k t}$ counts the number of PhDs theses in mathematics in location $k$ and year $t$, and the variable within 25 miles $_{k}$ indicates locations that are within 25 miles of at least one BRP book in mathematics. A potential concern with these tests is that universities who acquired BRP books may differ systematically from other universities. For example, universities that bought BRP books may have been able to attract better faculty, who then produced more students. ${ }^{48}$ Importantly, however, there are no significant differences in pre-trends across locations (Figure 13), even though distant locations produce fewer $\mathrm{PhDs}$ on average.

OLS estimates indicate that locations within 25 miles of BRP books produce 0.798 additional PhDs per year after the BRP. Relative to a mean of 0.358 before 1942, this implies a 2.2-fold increase (Table 8, column 1, significant at 10 percent). Maps of new PhDs confirm that new $\mathrm{PhD}$ grants became more concentrated around locations with BRP books after the BRP (Appendix Figure A10).

\section{B. New US Patents}

As a final test, we examine the effect of the BRP on private sector firms. Archival evidence from the records of J.W Edwards publishing house suggest that this impact may have been significant. For example, most of the copies of Beilstein's Handbuch der Organischen Chemie appear to have been sold to private sector firms. NUC data on library holdings indicate that 158 libraries bought a copy of Beilstein, which leaves 442 copies (in total 600 sold copies, Bokas and Edwards 2011, p. 25) for private firms. Another benefit of patents as a complementary measure to citations is that patents measure a more applied, business-relevant aspect of cumulative innovation.

Confirming the main results, analyses of patent data suggest a large increase in cumulative invention in response to the BRP. Before 1942, a total of 34 US patents cite at least one BRP book in the description of their invention. ${ }^{49}$ Afterwards, 200 patents cite BRP books. Beilstein, for example, is cited as relevant scientific knowledge in 0.304 patents per year before 1942, and 1.345 afterwards. For the average BRP book, patent references increase by 15 percent, from 0.005 per book and year to 0.024 (Figure 14).

\footnotetext{
${ }^{48}$ Using the expulsion of German Jews from German universities as a source of experimental variation, Waldinger (2010) shows that the quality of $\mathrm{PhD}$ advisors mattered greatly for the career outcome of $\mathrm{PhD}$ students in mathematics. By contrast, peer effects among faculty were much more limited (Waldinger 2012). ${ }^{49}$ Thirty patents cite a BRP chemistry book and 4 cite a BRP math book before $1942 ; 190$ patents cite a BRP chemistry book and 10 cite a BRP math book after 1941 (530 and 150 percent more, respectively.) The larger number of chemical patents reflects the exceptional effectiveness of patents in chemicals (e.g. Moser 2012a).
} 


\section{CONCLUSIONS}

This paper has shown that soft intellectual property rights for content can promote the creation of new science. In 1942, the US Book Republication Program allowed US publishers to produce exact copies of science books whose copyrights were owned by German enemies of war. Combining two complementary identification strategies, we find that this change in copyright policy led a 67-percent increase in English-language citations to BRP books.

Highlighting the importance of human capital, these effects are strongest in mathematics, a discipline in which knowledge depends almost exclusively on human, rather than physical capital. Effects were also larger for books by German Jewish émigrés who fled to the United States. Yet books by émigrés cannot explain the overall increase in citations.

Lower prices for books are the main mechanism by which the BRP affected US science. By breaking publishers' monopoly for science books, the BRP reduced the price of content by an average of 25 percent. Intensity regressions indicate that each 10-percent decline in price was associated with a 45-percent increase in citations. Data on library holdings and loans indicate that lower prices allowed BRP books to reach less affluent institutions who made them available to a new group of scientists. A geographic analysis of citations shows that citations increased most near libraries with BRP books. Two alternative measures of scientific output and innovation - new $\mathrm{PhDs}$ theses and patents - confirm the main results.

Our findings highlight a key tradeoff for intellectual property rights. Basic levels of copyright protection can be welfare-improving because they strengthen incentives for original authorship and creativity (e.g., MacGarvie and Moser 2013, Giorcelli and Moser 2017). Yet copyrights also constrain the use of copyrighted content in future creativity. The findings of this paper highlight the exceptional welfare costs of long-lived copyrights for science, a field in which new advances depend critically on access to existing work (Scotchmer 1991, Furman and Stern 2011, Williams 2013, Iaria et al 2016).

Compared with other media, such as music, news, or film, the incentive effects of copyrights are small for academic science. This is mostly due to the structure of scientific publishing. Scientists typically transfer copyrights to publishers without compensation, and sometimes even pay for open access to their work. Compared with other types of intellectual property, such as patents, the incentives of the original innovator and the right owner are misaligned. Authors generally favor wide-spread distribution, whereas publishers maximize profits, and have an incentive to charge a monopoly price for new research. 


\section{REFERENCES}

Katalog. Systematisches Verzeichnis der Schweizerischen oder die Schweiz betreffenden Veröffentlichungen (vols. 1921-1939 and 1931-1940), Bern, H. Huber.

Library of Congress, 1968-1981. The National Union Catalog, pre-1956 Imprints:

A Cumulative Author List Representing Library of Congress Printed Cards and Titles Reported by Other American Libraries, Compiled and Edited with the Cooperation of the Library of Congress and the National Union Subcommittee of the Resources Committee of the Resources and Technical Services Division, American Library Association. London, Mansell.

Abadie, Alberto, and Guido Imbens. 2011. "Simple and Bias-corrected Matching Estimators for Average Treatment Effects." Journal of Business \& Economics Statistics 29 (1): 1-11.

Alien Property Custodian Office. 1944. "Book Republication Program: Titles Suggested for Republication, an Alphabetical List with a Subject Index." United States.

Ammon, Ulrich. 2001. The Dominance of English as a Language of Science: Effects on Other Languages and Language Communities. Berlin: Mouton de Gruyter

Beilstein, Friedrich Konrad. 1918. Beilstein's Handbuch der Organischen Chemie. Berlin: J. Springer.

Bird, Kai and Martin J. Sherwin. 2005. "American Prometheus. The Triumph and Tragedy of J. Robert Oppenheimer." New York. Alfred A. Knopf.

Bokas, Carol and Jim Edwards. 2011. Then and Now. A History Thomas Edwards Senior, His Descendants, and Related Families, 1826-2011. Ann Arbor Editions.

Buccafusco, Christopher and Sprigman, Christopher Jon, "The Creativity Effect." University of Chicago Law Review, Vol. 78, p. 31, 2011

Cagé, Julia, Nicolas Hervé, and Marie-Luce Viaud (2017), "The Production of Information in an Online World: Is Copy Right?” Working Paper, Science Po Paris.

Cantoni, Davide, Yuyu Chen, David Y. Yang, Noam Yuchtman, Y. Jane Zhang (2017), "Curriculum and Ideology." Journal of Political Economy, 125 (2): 338-392.

Danaher, Brett, Michael D. Smith, Rahul Telang, and Siwen Chen. 2014. "The Effect of Graduated Response Anti-Piracy Laws on Music Sales: Evidence from an Event Study in France." Journal of Industrial Economics, 62(3): 541-553.

Davis, Philip M.., Bruce V. Lewenstein, Daniel H. Simon, James G. Booth, and Matthew J.L. Connolly. "Open Access Publishing, Article Downloads, and Citation: Randomised Controlled Trial." British Medical Journal, 2008.

DiCola, Peter. 2013. "Money from Music: Survey Evidence on Musicians' Revenue and Lessons About Copyright Incentives." Arizona Law Review 301.

Evans, James A., and Jacob Reimer. 2009. "Open Access and Global Participation in Science." Science 323 (5917): 1025.

Eysenbach, Gunther. 2006. "Citation Advantage of Open Access Articles." Public Library of Science Biology 4 (5): 692.

Furman, Jeffrey, and Scott Stern. 2011. "Climbing atop the Shoulders of Giants: The Impact of Institutions on Cumulative Research." American Economic Review 101 (5): 1933-63.

Galasso, Alberto and Mark Schankerman. 2015. "Patents and Cumulative Innovation: Causal Evidence from the Courts." The Quarterly Journal of Economics 130 (1): 317-369.

Giorcelli, Michela, and Petra Moser. 2017. "Copyright and Creativity: Evidence from Italian Operas." Working Paper. http://ssrn.com/abstract=2505776.

Goldstein, Paul. 2003. Copyright's Highway: From Gutenberg to the Celestial Jukebox. Stanford, CA: Stanford University Press, Revised Edition. 
Greer, John Michael, Pinelopi K. Goldberg, and Panle Jia. 2006. "Estimating the effects of global patent protection in pharmaceuticals: a case study of quinolones in India." The American Economic Review, vol. 96 no. 5, pp. 1477-1514.

Hargittai, István. 2006. Martians of Science: Five Physicists Who Changed the Twentieth Century. Oxford: Oxford University Press.

Heald, Paul J. 2014. "How Copyrights Keeps Works Disappeared." Journal of Empirical Legal Studies 11 (4): 829-866.

Iaria, Alessandro, Carlo Schwarz, and Fabian Waldinger. forthcoming. "Frontier Knowledge and Scientific Production: Evidence from the Collapse of International Science." Quarterly Journal of Economics.

Jannot, Anne-Sophie, Thomas Agoritsas, Angèle Gayet-Ageron, and Thomas V. Perneger. 2013. "Citation Bias Favoring Statistically Significant Studies was Present in Medical Research." Journal of Clinical Epidemiology 66 (3): 296-301.

Landes, William M., and Richard A. Posner. 1989. "An Economic Analysis of Copyright Law." The Journal of Legal Studies 18 (2): 325-363.

Li, Xing, Megan MacGarvie, and Petra Moser. Forthcoming. "Dead Poets' Property - How Does Copyright Influence Price?" RAND Journal of Economics.

Luckenbach, Reiner. 1981. "The Beilstein Handbook of Organic Chemistry: The First Hundred years." Journal of Chemical Information and Computer Sciences, vol. 21 no. 2, pp. 82-83.

MacGarvie, Megan and Petra Moser. 2013. "Copyright and the Profitability of Authorship: Evidence from Payments to Writers in the Romantic Period," in Shane M. Greenstein, Avi Goldfarb, and Catherine Tucker (eds.) The Economics of Digitization Chicago, Illinois: University of Chicago Press.

McCabe, Mark J., and Christopher M. Snyder. 2014. "Identifying the Effect of Open Access on Citations Using a Panel of Science Journals," Economic Inquiry, October, vol. 52, no. 4, pp. 1284-1300.

McCabe, Mark J., and Christopher M. Snyder. 2015. "Does Online Availability Increase Citations? Theory and Evidence from a Panel of Economics and Business Journals." Review of Economics and Statistics 97 (1): 144-165.

Meho, Lokman I., and Kiduk Yang. 2007. "Impact of Data Sources on Citation Counts and Rankings of LIS Faculty: Web of Science Versus Scopus and Google Scholar." Journal of the American Society for Information Science and Technology 58 (13): 2105-2125.

Menell, Peter S. "An Analysis of the Scope of Copyright Protection for Application Programs.” Stanford Law Review, Vol. 42, No. 5 (May, 1989), pp. 1045-1104.

Moser, Petra. 2012a. "Innovation without Patents: Evidence from World's Fairs." The Journal of Law \& Economics 55 (1): 43-74

Moser, Petra. 2012b. "Taste-Based Discrimination: Evidence from a Shift in Ethnic Preferences after WWI." Explorations in Economic History 49 (2): 167-188.

Moser, Petra and Alessandra Voena. 2012. "Compulsory Licensing: Evidence from the Trading with the Enemy Act." American Economic Review, 102(1): 396-427.

Moser, Petra, Alessandra Voena, and Fabian Waldinger. 2014. "German-Jewish Émigrés and US Invention." American Economic Review 104 (10): 3222-3255.

Myron, Paul. 1945. "The Work of the Alien Property Custodian." Law and Contemporary Problems 11: 76-91.

Nordhaus, William D. 1969. "An economic theory of technological change." The American Economic Review 59(2): 18-28.

Nagaraj, Abishek. forthcoming. "Does Copyright Affect Re-use? Evidence from the Google Books Digitization Project." Management Science. 
Oberholzer-Gee, Felix, and Koleman Strumpf. 2007. "The Effect of File Sharing on Record Sales: An Empirical Analysis." Journal of Political Economy, 115 (1): 1-42.

Prat, Andrea. Forthcoming. "Media Power." Journal of Political Economy.

Paris, Gianmarco, G. De Leo, P. Menozzi, M. Gatto. 1998. "Region-based Citation Bias in Science." Nature 396 (6708): 210-210.

Reimers, Imke. 2015. "Copyright and Generic Entry in Book Publishing." Northeastern University, Working Paper.

Richards, Pamela Spence. 1981. "Gathering Enemy Scientific Information in Wartime: The OSS and the Periodical Republication Program." The Journal of Library History (19741987), 16 (2): 253-264.

Roach, Michael, Wesley M. Cohen. 2012. "Lens or Prism? Patent Citations as a Measure of Knowledge Flows from Public Research." Management Science.

Rob, Rafael, and Joel Waldfogel. 2006. "Piracy on the high C's: Music downloading, sales displacement, and social welfare in a sample of college students." The Journal of Law and Economics 49(1): 29-62.

Scotchmer, Suzanne. 1991. "Standing on the Shoulders of Giants: Cumulative Research and the Patent Law." The Journal of Economic Perspectives 5 (1): 29-41.

Strauss, Herbert A., Werner Röder, Belinda Rosenblatt, and Hannah Caplan. 1983. International Biographical Dictionary of Central European Émigrés 1933-1945. Vol II: Arts, Sciences and Literature. New York: K.G. Saur.

Squicciarini, Mara P., and Nico Voigtländer. 2015. "Human capital and industrialization: Evidence from the age of enlightenment." The Quarterly Journal of Economics 130.4 (2015): 1825-1883.

Varian, Hal R. 2005. "Copying and Copyright.” The Journal of Economic Perspectives 19 (2): 121-138.

Waldinger, Fabian. 2010. "Quality Matters: The Expulsion of Professors and the Consequences for Ph.D. Student Outcomes in Nazi Germany," Journal of Political Economy, 118 (4): 787-831.

Waldinger, Fabian. 2012. "Peer Effects in Science - Evidence from the Dismissal of Scientists in Nazi Germany," The Review of Economic Studies, 79 (2): 838-861.

Waldinger, Fabian. 2016. "Bombs, Brains, and Science - The Role of Human and Physical Capital for the Creation of Scientific Knowledge." Review of Economics and Statistics, 98 (5): 811-831.

Wang, Jian, Reinhilde Veugelers, and Paula Stephan. 2017. "Bias against novelty in science: A cautionary tale for users of bibliometric indicators." Research Policy, 46 (8): 1416-1436.

Webster, Charles K. and Noble Frankland. 1961. The Strategic Air Offensive Against Germany 1939-1945. vol. 1-4, London: Her Majesty's Stationary Office.

Williams, Heidi. 2013. "Intellectual Property Rights and Innovation: Evidence from the Human Genome Project." Journal of Political Economy 121(1): 1-27.

Williamson, Samuel H. 2016. "Seven Ways to Compute the Relative Value of a U.S. Dollar Amount, 1774 to present." MeasuringWorth.

Tabakovic, Haris, and Thomas Wollmann. 2016. "The Impact of Money on Science: Evidence from Unexpected NCAA Football Outcomes". Working Paper. 
FigURE 1 - CITATIONS TO BRP BOOKS

FROM NEW WORK IN ENGLISH VERSUS OTHER LANGUAGES

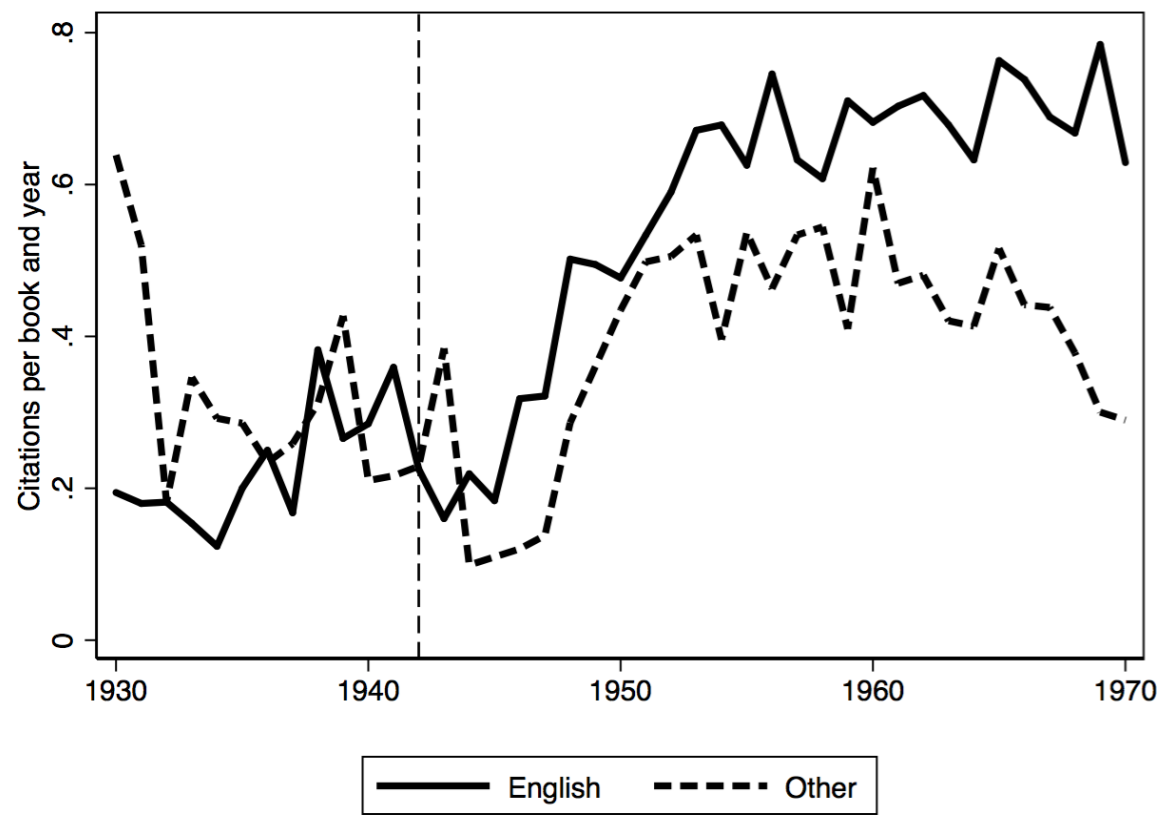

Notes: English are citations to BRP books by English-language authors by the publication year of the citing publication. Other are citations from authors publishing in other languages). Citations collected from Google Scholar (http://scholar.google.com, accessed July $1^{\text {st }}$ September $\left.25^{\text {th }}, 2014\right)$, and manually assigned to a publication language.

Figure 2 - TIME-VARYING EFFECTS, ENGLISH VS. NON-ENGLISH CITATIONS TO BRP BOOKS

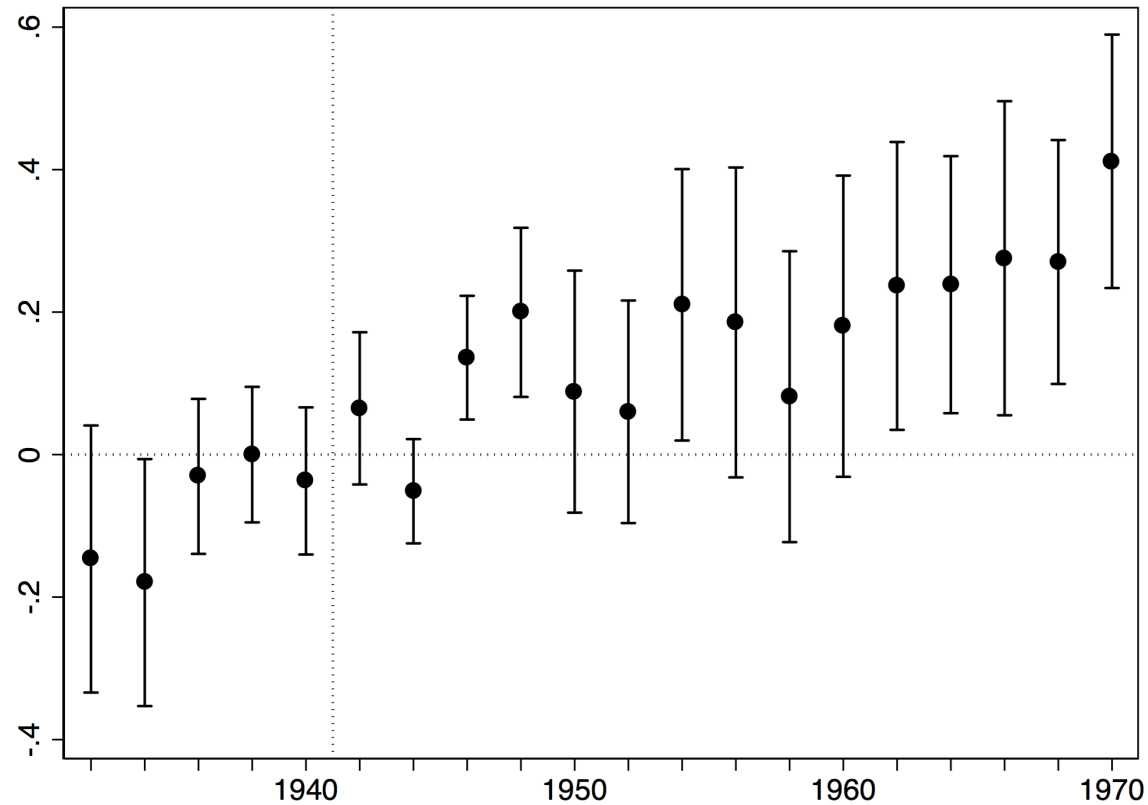

Notes: Estimates of $\beta_{s}$ (with a 95-percent confidence interval) in the OLS regression cites $_{\text {ilt }}=$ $\Sigma_{s} \beta_{s}$ English ${ }_{l} * \tau_{s}+$ book $_{i}+\tau_{t}+\varepsilon_{i l t}$ for two-year intervals 1930-1931,..,1969-70, with years before 1930 as the excluded period. The dependent variable cite $_{i l t}$ counts citations to 273 BRP books $i$ in language $l$ (English vs. non-English) in year $t$. The indicator English equals 1 for citations from English-language authors. Book $k_{i}$ is a vector of book fixed effects; $\tau_{t}$ indicates 2-years intervals 1930-31, ...1969-70. Standard errors are clustered at the book level. 
Figure 3 - Citations to a Matched SAMPle of BRP And Swiss Books

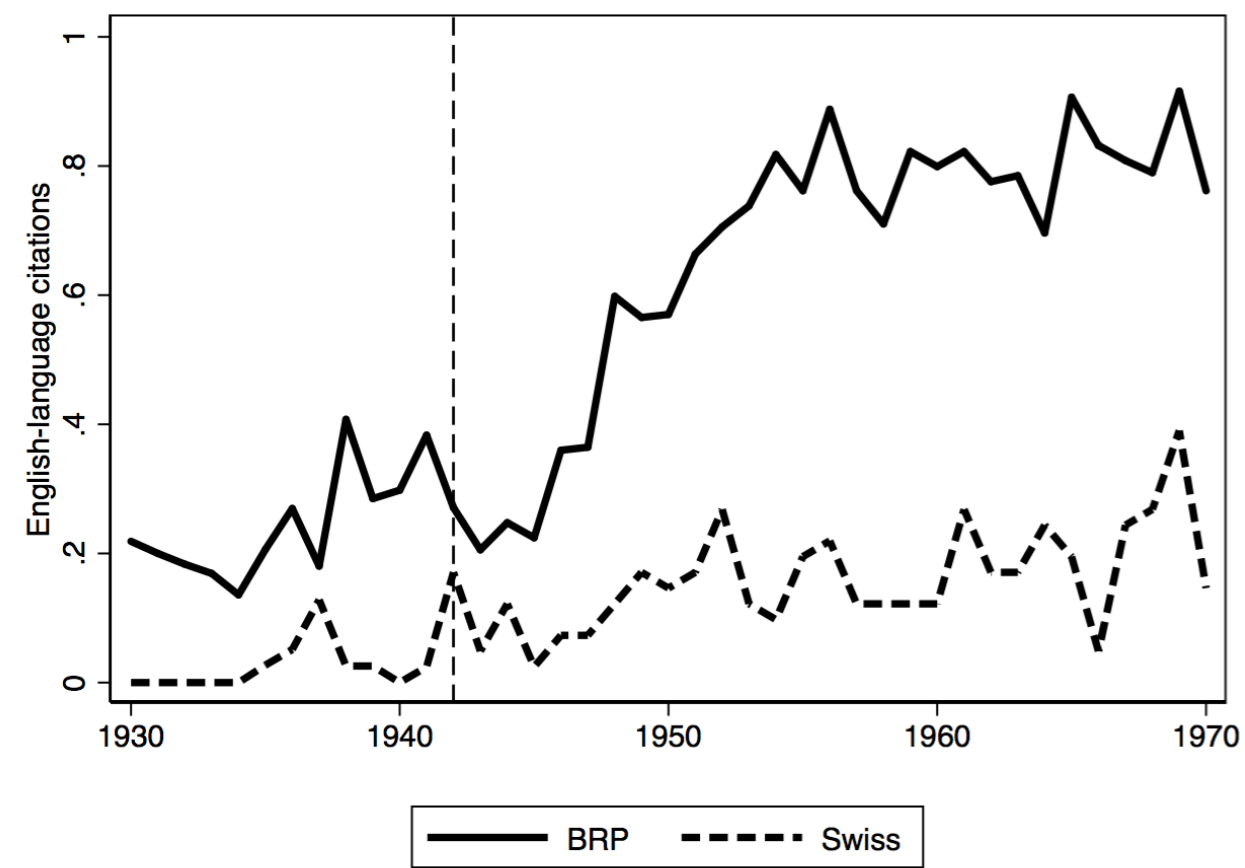

Notes: Citations for a matched sample of 214 BRP books and 39 Swiss books. Books are matched with a Mahalanobis propensity score procedure using research fields and the stock of pre-1942 Non-English citations as matching variables.

Figure 4 - Time-VARying Effects, BRP vs. Swiss, MAtched SAMPLE

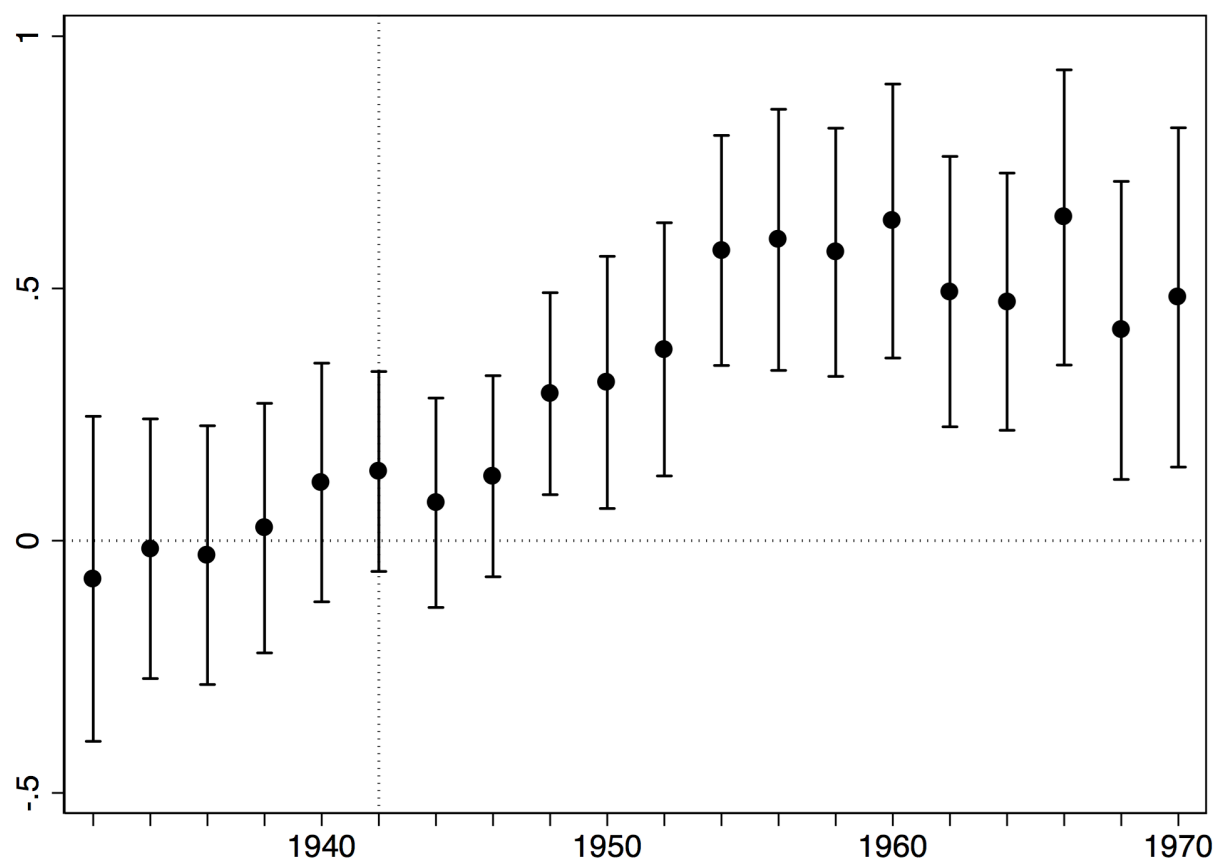

Notes: Estimates of $\beta_{s}$ with a 95-percent confidence interval in the OLS regression cites $_{i t}=\Sigma_{s}$ $\beta_{s} B R P_{i} * \tau_{s}+$ book $_{i}+\tau_{t}+\varepsilon_{i t}$ for two-year intervals 1930-1931,..,1969-70, with years before 1930 as the excluded period. The dependent variable cite $_{i t}$ counts English-language citations to 214 BRP and 39 Swiss book $i$ in year $t$. Book $k_{i}$ is a vector of book fixed effects; $\tau_{t}$ indicates 2-years intervals 1930-31, ...1969-70. Standard errors are clustered at the book level. 
Figure 5- Time-VARying EfFects of Changes in Price

ENGLISH VS. OTHER LANGUAGE CiTATIONS TO BPR BOOKS

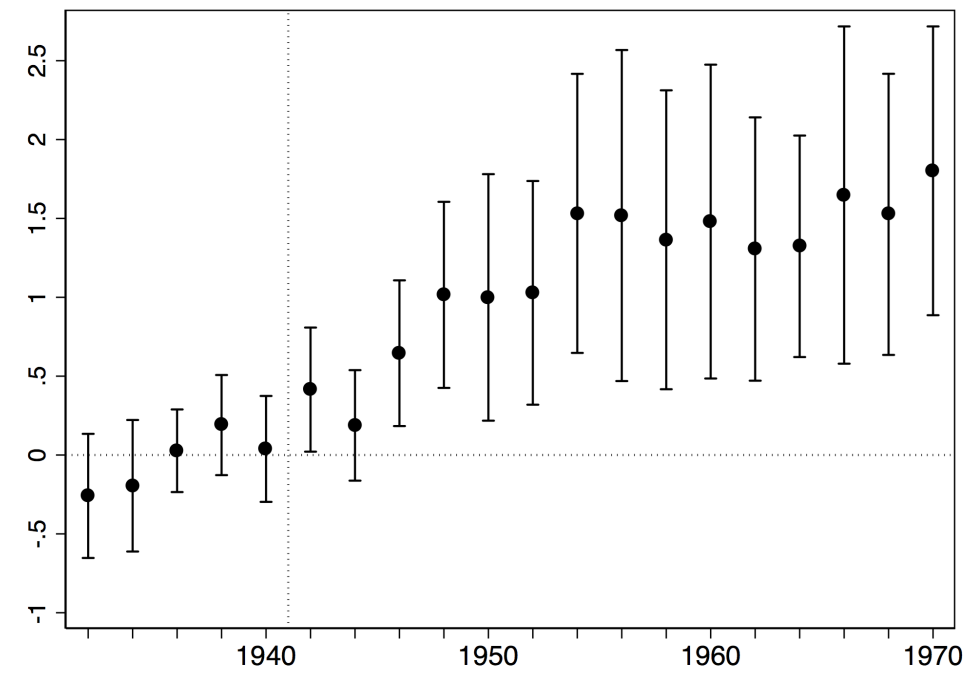

Notes: Estimates of $\theta_{s}$ with a 95-percent confidence interval in the OLS regression cites $_{i l t}=\alpha$ English $_{l}+\beta$ English $_{l} *$ post $_{t}+\Sigma_{s} \theta_{s} \Delta p_{i} *$ English $_{l} * \tau_{s}+$ book $_{i}+\tau_{t}+\varepsilon_{\text {ilt }}$ for two-year intervals $1930-131, \ldots, 1969-70$, with years before 1930 as the excluded period. The dependent variable cite $_{i l t}$ counts citations to BRP book $i$ in language $l$ and year $t$. The indicator English equals 1 for citations from English-language authors. Book $k_{i}$ is a vector of book fixed effects; $\tau_{t}$ indicates 2-years intervals 1930-31,...1969-70. The variable $\Delta p$ measures the difference between the original price and the BRP price for book $i$, divided by the original price. Standard errors are clustered at the book level.

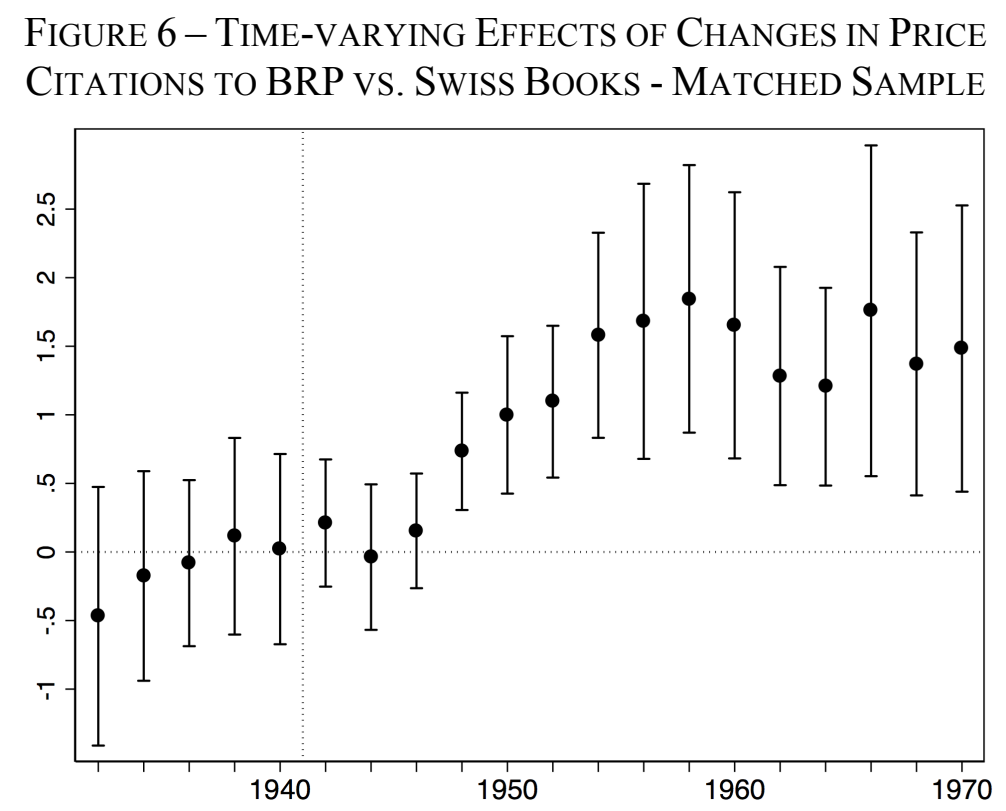

Notes: Estimates of $\theta_{s}$ with a 95-percent confidence interval in the OLS regression cites $_{i t}=\beta$ $B R P_{i} *$ post $_{t}+\Sigma_{s} \theta_{s} \Delta p_{i} * B R P_{i} * \tau_{s}+$ book $_{i}+\tau_{t}+\varepsilon_{i t}$ for two-year intervals 1930-

$1931, \ldots, 1969-70$, with years before 1930 as the excluded period. The dependent variable cite $_{i t}$ counts citations to a matched sample of 214 BRP and 39 Swiss book $i$ in year $t$. Book $_{i}$ is a vector of book fixed effects; $\tau_{t}$ indicates 2 -years intervals 1930-31, ...1969-70. The variable $\Delta p$ measures the difference between the original price and the BRP price, divided by the original price. Standard errors are clustered at the book level. 
Figure 7 - CiTATIONS PER BOOK AND YEAR FOR BRP BOOKS IN MATHEMATICS

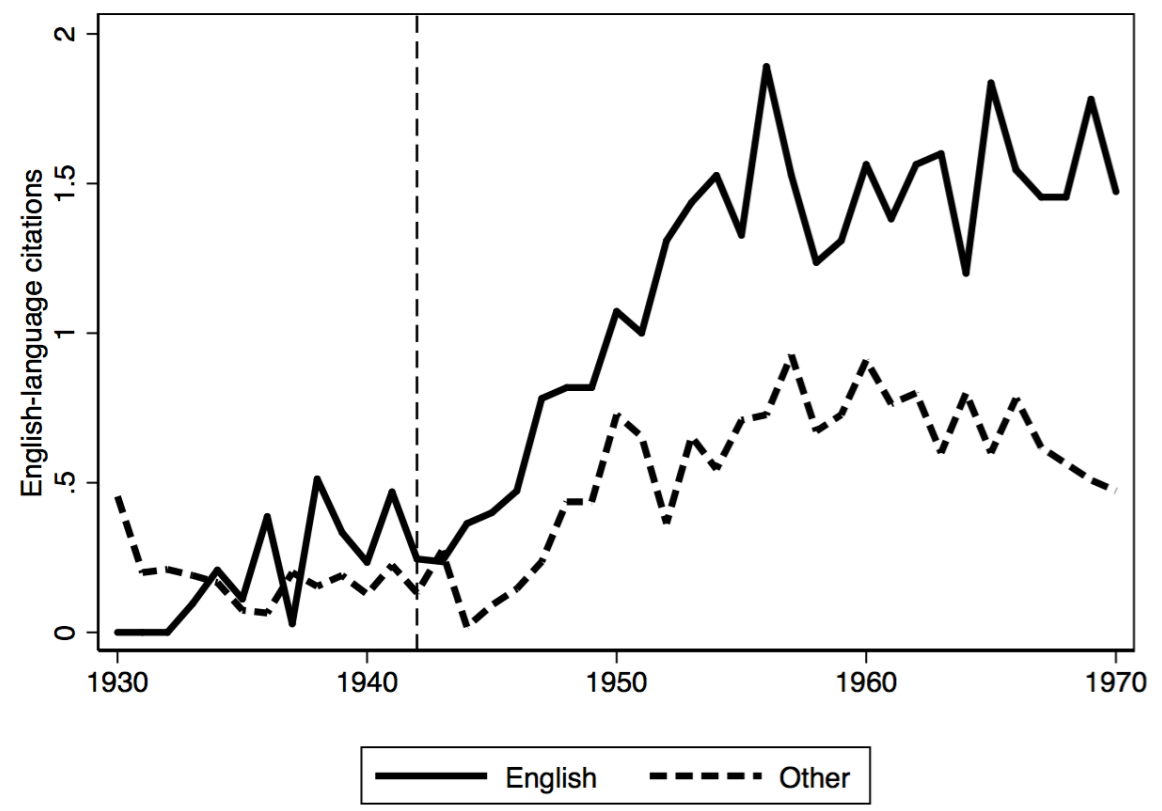

Notes: English are citations by to BRP books by English-language authors. Other measures citations to the same books by other language authors. Citations to BRP books from Google Scholar (http://scholar.google.com, accessed July $1^{\text {st }}$-September $25^{\text {th }}, 2014$ ).

Figure 8 - Time-VARYing EFFects of Price in Mathematics

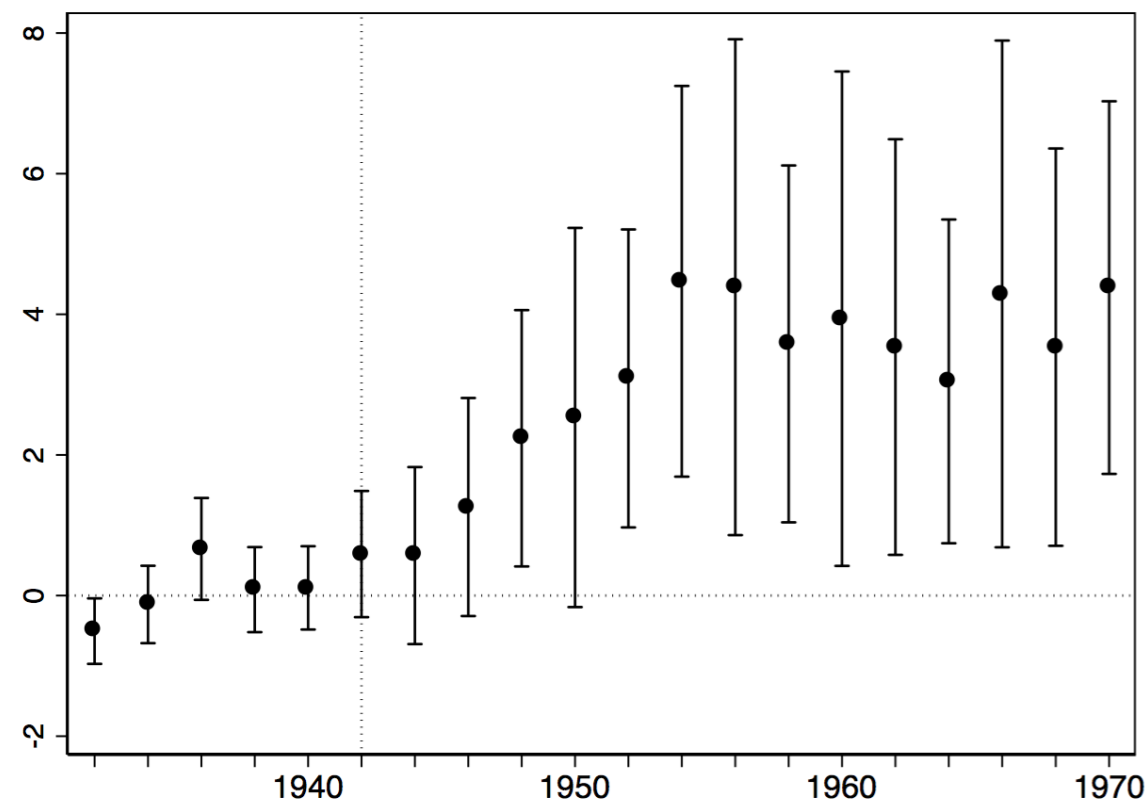

Notes: Estimates of $\theta_{s}$ (with a 95-percent confidence interval) in the OLS regression cites $_{\text {ilt }}=$ $\alpha$ English $_{l}+\beta$ English $_{l} *$ post $_{t}+\Sigma_{s} \theta_{s} \Delta p_{i} *$ English $_{l} * \tau_{s}+$ book $_{i}+\tau_{t}+\varepsilon_{i t}$ for two-year intervals $1930-1931, \ldots, 1969-70$, with years before 1930 as the excluded period. The dependent variable cite $_{i t}$ counts citations to BRP math book $i$ in year $t$. The indicator English equals 1 for citations by English-language authors. Book $k_{i}$ is a vector of book fixed effects; $\tau_{t}$ indicates 2-years intervals 1930-31, ...1969-70. The variable $\Delta p$ measures the difference between the original price and the BRP price, divided by the original price. Standard errors are clustered at the book level. 
Figure 9 - CitATIONS TO BRP BOOKS BY ÉMIGRÉs COMPARED WITH OTHER BOOKS

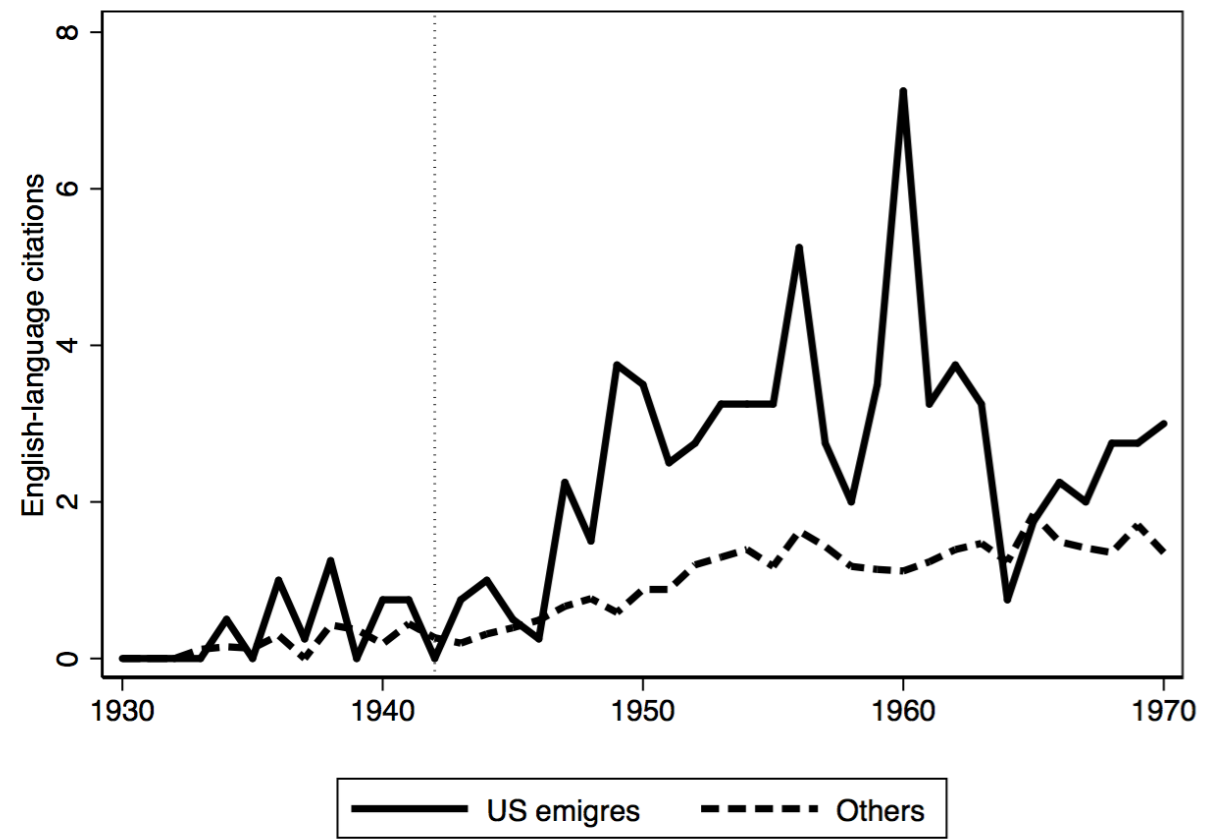

Notes: US emigres captures English-language citations per book and year for five BRP books by seven mathematicians who emigrated to the United States after 1932. Others counts English-language citations to BRP books by other authors who did not move to the United States. Data on émigrés from the Dictionary of Central European Émigrés (Straus et al. 1983) and Mathematics Genealogy Project. 
FigURE 10 - BRP BOOKS (TOP) AND SwISS (BOTTOM) BOOKS IN US LIBRARIES
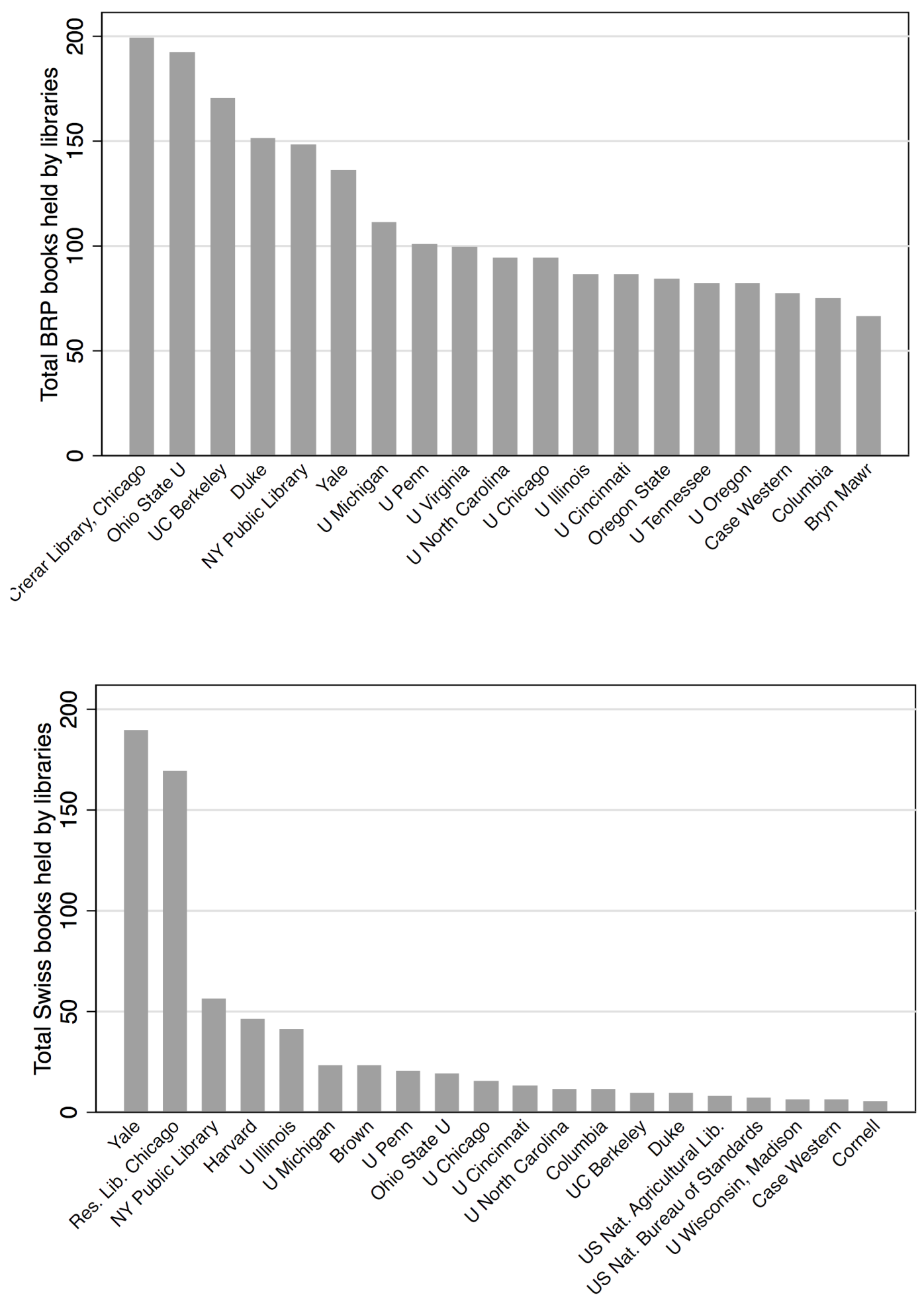

Notes: Counts of BRP books (top panel) and Swiss books (bottom panel) in the holding of a given library. For example, the Crerar Library owned 199 BRP books (top) and 15 Swiss books by 1956. Data on historical library holdings collected from the National Union Catalog (Mansell 1968-1981), accessed at the Hoover Institution Library and Archives. 
FIGURE 11 - BRP BOOKS ON LOAN, 1930-1970

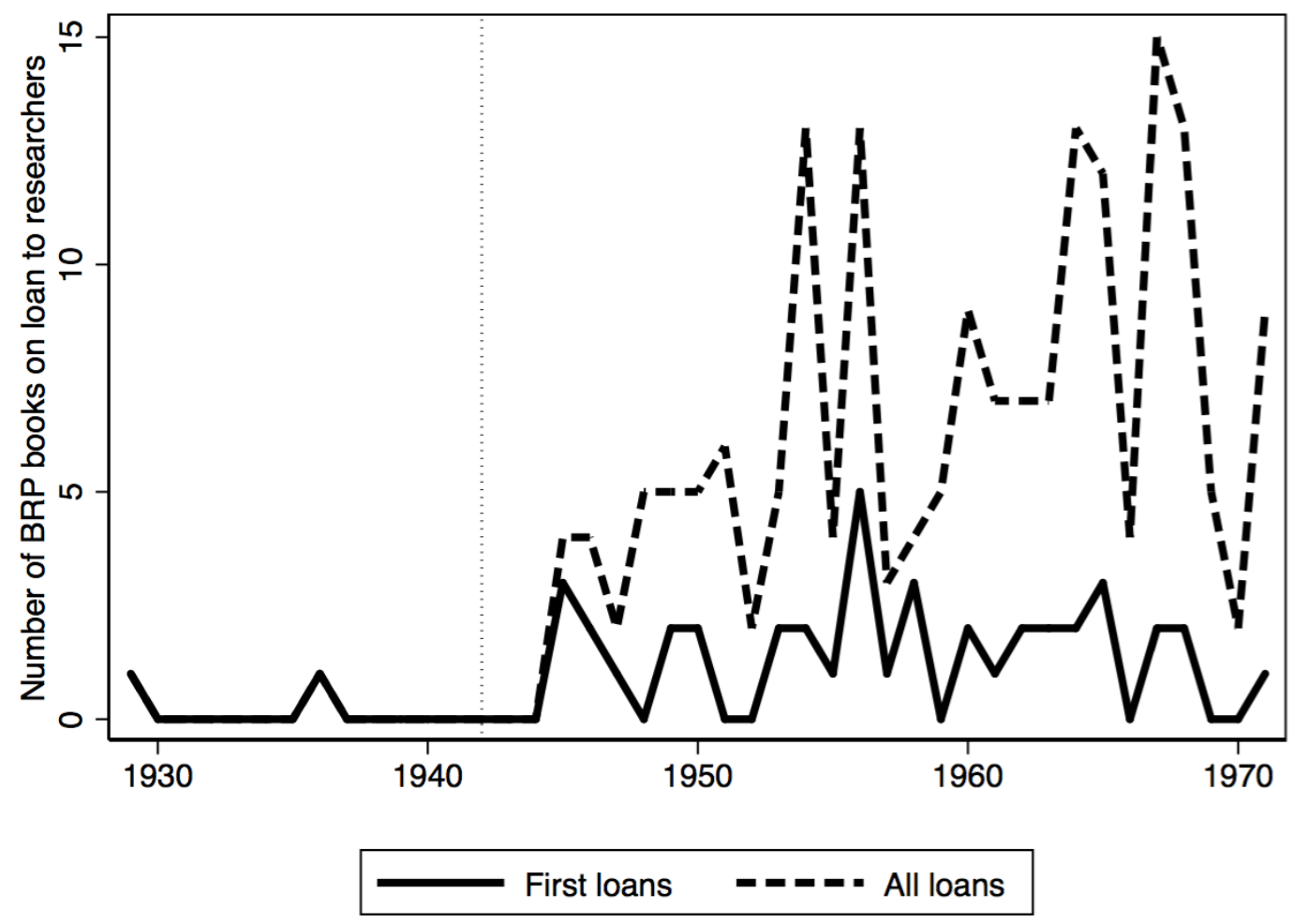

Notes: BRP books on loan to researchers from Stanford's library in year $t$. The solid line (First loans) represents the number of BRP books that were first lent to a researcher in year $t$. The interrupted line (All loans) plots the total number of BRP books on loan in year $t$.

Figure 12 - LOCATIONS OF BRP MATH BoOK AND Citing MATHEMATICIANS

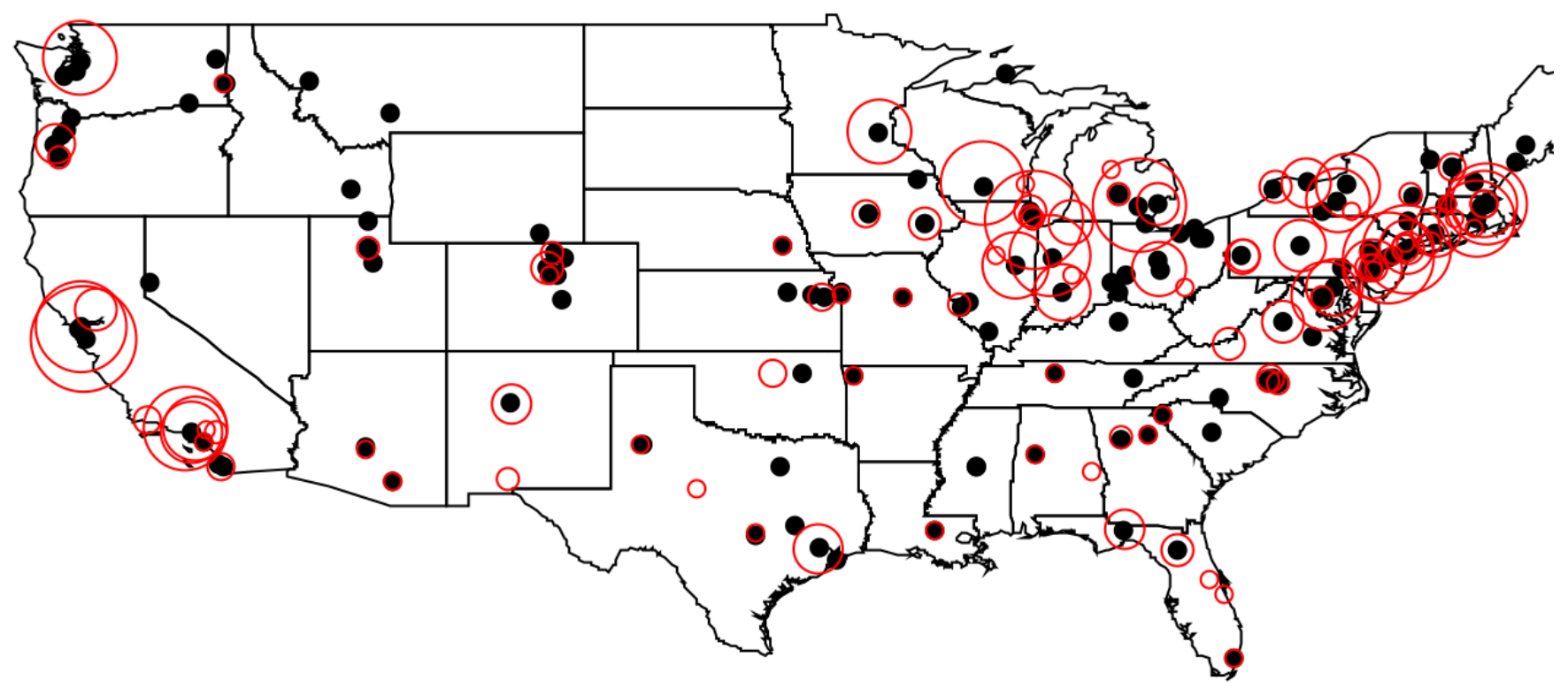

Notes: Black circles are libraries that had acquired BRP math books by 1956 . Red circles show the locations of authors who cite BRP math book after the 1942; the size of the red circle represents the number of citations. To identify the locations of citing authors we use records of $\mathrm{PhD}$ granting institution of advisors and advisees in the Mathematics Genealogy Project (accessed January 28th-March 10, 2016). 
Figure 13 - New PhDs Per YeAr, By Distance Of Location From BRP Library

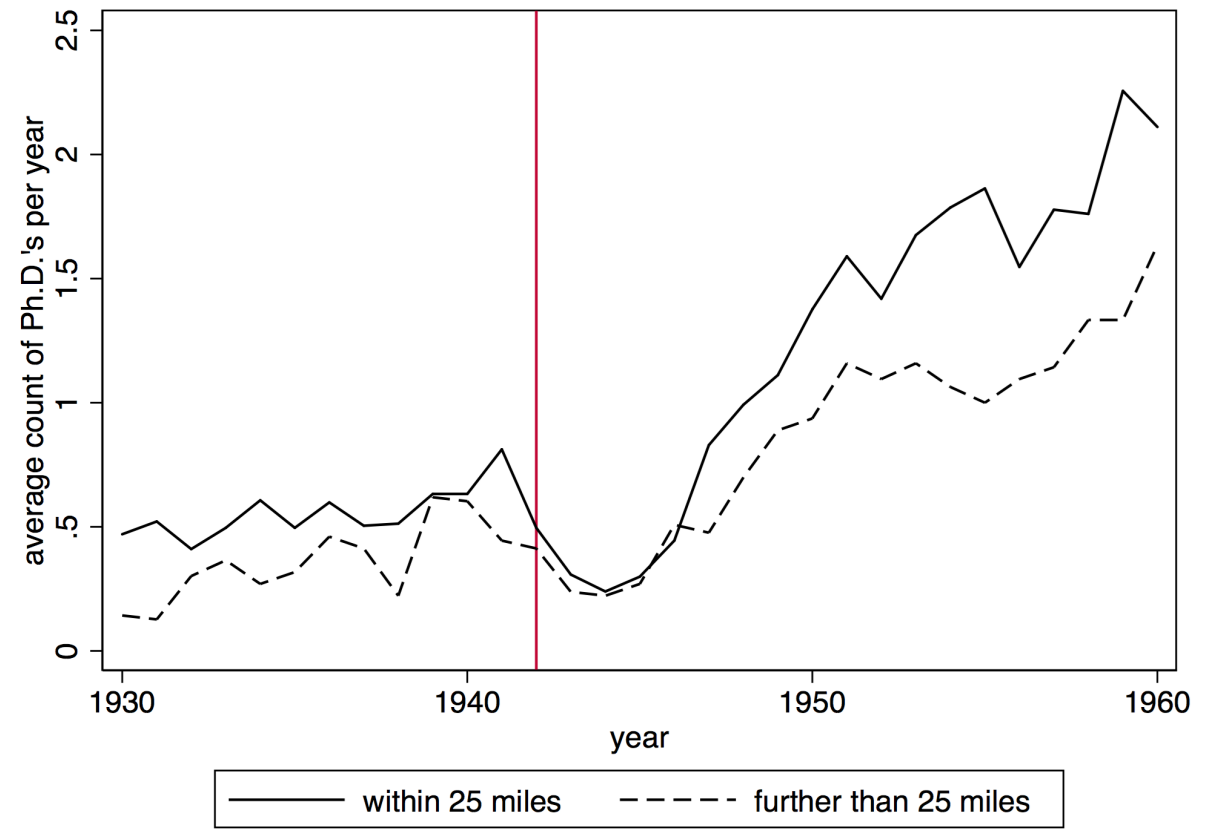

Notes: Citations by scientific publications per book and citation year for 55 BRP math books., by distance of the PhD-granting institution from a library holding at least one BRP book. We have collected data on the geographic locations of authors from records of $\mathrm{PhD}$ granting institution of advisors and advisees in the Mathematics Genealogy Project (http://www.genealogy.ams.org, accessed January 28th-March 10, 2016). Data on libraries holdings were constructed from the records of the National Union Catalog (Mansell 19681981) at the Hoover Institution Library and Archives.

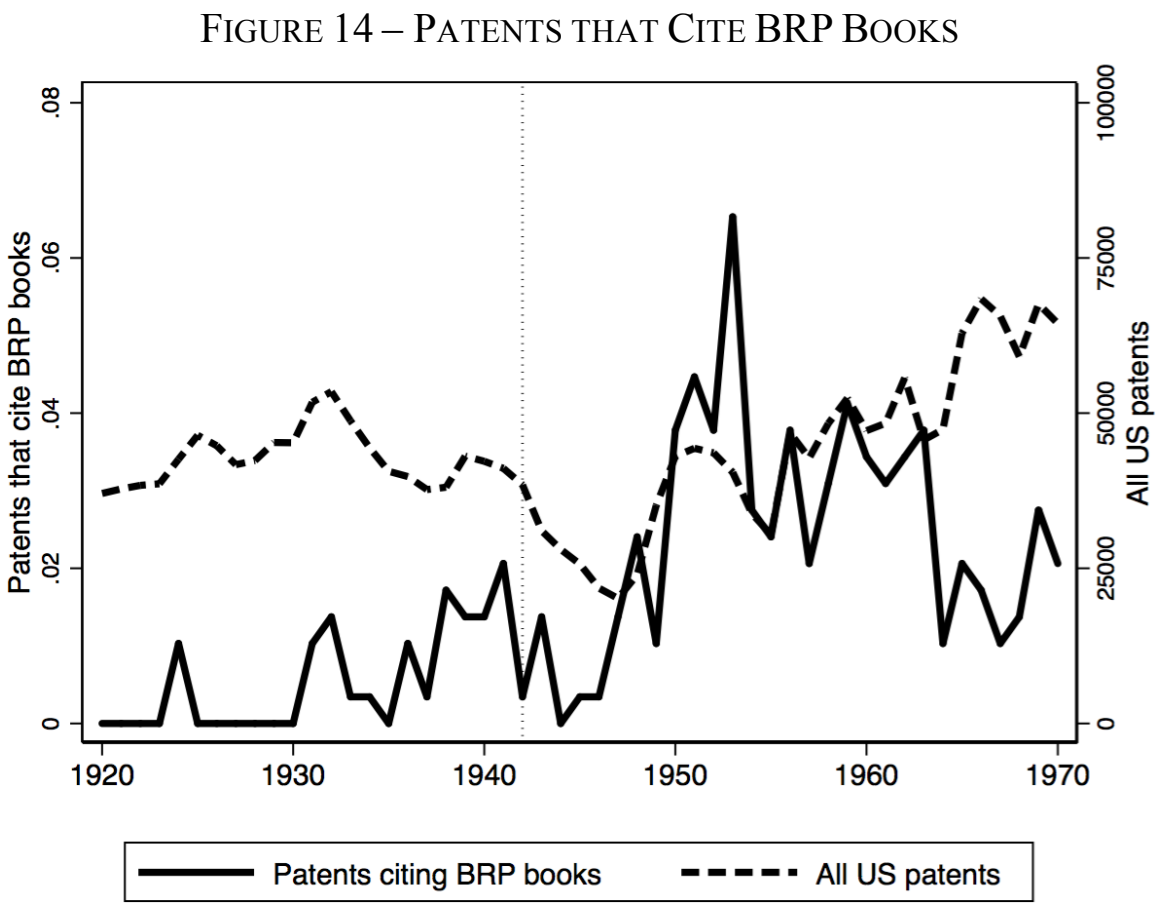

Notes: Patents that cite BRP books as relevant scientific knowledge (per filing year, solid line), compared with the total number of US patent filings in the same year. Patents collected from Google Patents (http://patents.google.com, accessed January $1^{\text {st }}$-April $30^{\text {th }}, 2016$ ). 
TABLE 1 - OLS AND QML POISSON REGRESSIONS

\begin{tabular}{lcccc}
\hline \hline & \multicolumn{3}{c}{ OLS (1-3) } & Poisson (4) \\
\cline { 2 - 5 } & $(1)$ & $(2)$ & $(3)$ & $(4)$ \\
\hline & & & & \\
English & -0.036 & -0.034 & -0.034 & \\
English x post & $(0.042)$ & $(0.039)$ & $(0.042)$ & \\
& $0.211^{* * *}$ & $0.229^{* * *}$ & $0.229 * * *$ & $0.497 * * *$ \\
Citation year FE & $(0.066)$ & $(0.061)$ & $(0.067)$ & $(0.157)$ \\
Book FE & Yes & Yes & Yes & Yes \\
Field * Citation year FE & Yes & Yes & No & Yes \\
Publication year FE & No & Yes & No & No \\
Field FE & No & No & Yes & No \\
R-squared & No & No & Yes & No \\
N & 0.357 & 0.401 & 0.117 & - \\
Pre-1942 mean & 19,680 & 19,162 & 19,162 & 18,610 \\
Standard errors in parentheses clustered at the book level. *** $\mathrm{p}<0.01, * * \mathrm{p}<0.05, * \mathrm{p}<0.1$ \\
\hline \hline
\end{tabular}

Notes: Columns (1-3) estimate OLS; the dependent variable measures citations to book $i$ per year $t$ between 1920 and 1970. Column (4) estimates quasi-maximum likelihood (QML)

Poisson regressions to address the count data characteristics of citations. The indicator English equals 1 for citations by English-language authors; the control group are citations to the same book from authors in other languages. The variable post equals one for years after 1941. 
TABle 2 - OLS AND QML Poisson REgRessions, MATChed SAMPLE

\begin{tabular}{lcccc}
\hline \hline & \multicolumn{3}{c}{ OLS (1-3) } & Poisson (4) \\
\cline { 2 - 5 } & $(1)$ & $(2)$ & $(3)$ & $(4)$ \\
\hline & & & 0.116 & \\
BRP & & & $(0.143)$ & \\
BRP x post & $0.386^{* * *}$ & $0.376^{* *}$ & $0.438^{* * *}$ & -0.342 \\
& $(0.101)$ & $(0.156)$ & $(0.117)$ & $(0.402)$ \\
Citation year FE & Yes & Yes & Yes & Yes \\
Book FE & Yes & Yes & No & Yes \\
Field * Citation year FE & No & Yes & No & No \\
Publication year FE & No & No & Yes & No \\
Field FE & No & No & Yes & No \\
R-squared & 0.558 & 0.622 & 0.182 & - \\
N & 9,365 & 9,365 & 9,365 & 7,151 \\
Pre-1942 mean & .283 & .283 & .283 & .339 \\
\multicolumn{1}{c}{ Standard errors in parentheses clustered at the book level. $* * * \mathrm{p}<0.01, * * \mathrm{p}<0.05, * \mathrm{p}<0.1$} \\
\hline \hline
\end{tabular}

Notes: BRP and Swiss books are matched using the Mahalanobis propensity score algorithm with fields and pre-1942 average non-English language citations per year as matching variables. Columns (1-3) estimate OLS; the dependent variable measures English-language citations to book $i$ per year $t$ between 1920 and 1970. Column (4) estimates quasi-maximum likelihood (QML) Poisson regressions to address the count data characteristics of citations. The indicator $B R P$ equals 1 for 214 books that were licensed to US publishers under the 1942 Book Republication Program (BRP). The control group includes 39 Swiss books that were not available for licensing due to Switzerland's neutrality during the war. The variable post equals for years after 1941 . 


\begin{tabular}{lccc}
\hline \hline & $(1)$ & $(2)$ & $(3)$ \\
\hline English & & & \\
& $-0.035^{* *}$ & $-0.035^{* *}$ & $-0.035^{* *}$ \\
BRP & $(0.014)$ & $(0.015)$ & $(0.014)$ \\
& & & 0.167 \\
English x BRP & & & $(0.112)$ \\
& 0.002 & 0.002 & 0.002 \\
BRP x post & $(0.048)$ & $(0.046)$ & $(0.047)$ \\
& $0.118^{*}$ & 0.127 & $0.156^{* *}$ \\
English x post & $(0.061)$ & $(0.077)$ & $(0.070)$ \\
& $0.115^{* *}$ & $0.115^{* *}$ & $0.115^{* *}$ \\
English x BRP x post & $(0.045)$ & $(0.048)$ & $(0.045)$ \\
& $0.202^{* *}$ & $0.202^{* *}$ & $0.202^{* *}$ \\
Citation Year FE & $(0.088)$ & $(0.086)$ & $(0.087)$ \\
Book FE & Yes & Yes & Yes \\
Subject * year FE & Yes & Yes & No \\
Publ. year \& subject FE & No & Yes & No \\
Pre-1942 Mean & No & No & Yes \\
R-squared & .300 & .300 & .300 \\
N & 0.372 & 0.414 & 0.132 \\
Standard errors in parentheses clustered at the book level. *** p<0.01, ** p $<0.05, * \mathrm{p}<0.1$ \\
\hline \hline
\end{tabular}

Notes: BRP and Swiss books are matched using the Mahalanobis propensity score algorithm with fields and pre-1942 average non-English language citations per year as matching variables. The dependent variable measures citations to book $i$ per year $t$ and language $c$ (English vs. other) between 1920 and 1970. The indicator English equals 1 for citations by English-language authors. The indicator $B R P$ equals 1 for 214 books that were licensed to US publishers under the 1942 Book Republication Program (BRP). The control group covers 39 Swiss books that were not available for licensing due to Switzerland's neutrality during the war. The variable post equals for years after 1941. 


\begin{tabular}{|c|c|c|c|c|}
\hline & $(1)$ & $\begin{array}{c}\text { OLS }(1-3) \\
(2)\end{array}$ & $(3)$ & $\begin{array}{c}\text { Poisson (4) } \\
(4)\end{array}$ \\
\hline English & $\begin{array}{l}-0.036 \\
(0.042)\end{array}$ & $\begin{array}{l}-0.034 \\
(0.039)\end{array}$ & $\begin{array}{l}-0.034 \\
(0.042)\end{array}$ & \\
\hline English $\mathrm{x}$ post & $\begin{array}{l}-0.077 \\
(0.091)\end{array}$ & $\begin{array}{l}-0.058 \\
(0.120)\end{array}$ & $\begin{array}{l}-0.070 \\
(0.091)\end{array}$ & $\begin{array}{c}0.010 \\
(0.208)\end{array}$ \\
\hline English $\mathrm{x} \Delta \mathrm{p} \times$ post & $\begin{array}{c}1.192 * * * \\
(0.344)\end{array}$ & $\begin{array}{c}1.188 * * * \\
(0.431)\end{array}$ & $\begin{array}{c}1.235 * * * \\
(0.342)\end{array}$ & $\begin{array}{c}1.470 * * * \\
(0.409)\end{array}$ \\
\hline$\Delta \mathrm{p}$ & & & $\begin{array}{c}0.241 \\
(0.176)\end{array}$ & \\
\hline Citation Year FE & Yes & Yes & Yes & Yes \\
\hline Book FE & Yes & Yes & No & Yes \\
\hline $\begin{array}{l}\text { Field FE * Citation } \\
\text { year FE }\end{array}$ & No & Yes & No & No \\
\hline Publication year FE & No & No & Yes & No \\
\hline Field FE & No & No & Yes & No \\
\hline R-squared & 0.366 & 0.411 & 0.138 & - \\
\hline $\mathrm{N}$ & 18,986 & 18,524 & 18,524 & 17,972 \\
\hline Pre-1942 Mean & 0.264 & 0.269 & 0.269 & 0.269 \\
\hline \multicolumn{5}{|c|}{ Standard errors in parentheses clustered at the book level. ${ }^{* * *} \mathrm{p}<0.01,{ }^{*} \mathrm{p}<0.05,{ }^{*} \mathrm{p}<0.1$} \\
\hline
\end{tabular}

Notes: The dependent variable measures citations to book $i$ per year $t$ between 1920 and 1970 . Column (1-3) estimate OLS. Column (7) estimates quasi-maximum likelihood (QML) Poisson regressions to address the count data characteristics of citations. The indicator English equals 1 for citations by English-language authors; the control group are citations to the same book from authors in other languages. The variable post indicates years after 1941 . The variable post indicates years after 1941. The variable $\Delta p$ measures the difference between the original price and the BRP price for book $i$, divided by the original price. 


\begin{tabular}{|c|c|c|c|c|}
\hline & $(1)$ & $\begin{array}{l}\text { OLS (1-3) } \\
(2)\end{array}$ & (3) & $\begin{array}{c}\text { Poisson (7) } \\
\text { (7) }\end{array}$ \\
\hline BRP & & & $\begin{array}{c}0.022 \\
(0.141)\end{array}$ & \\
\hline BRP x post & $\begin{array}{c}0.056 \\
(0.089)\end{array}$ & $\begin{array}{c}0.086 \\
(0.143)\end{array}$ & $\begin{array}{c}0.085 \\
(0.101)\end{array}$ & $\begin{array}{l}-0.315 \\
(0.448)\end{array}$ \\
\hline BRP $\times \Delta p \times$ post & $\begin{array}{c}1.116^{* * * *} \\
(0.376)\end{array}$ & $\begin{array}{l}1.060^{*} \\
(0.527)\end{array}$ & $\begin{array}{l}1.201 * * * \\
(0.361)\end{array}$ & $\begin{array}{l}-0.066 \\
(0.486)\end{array}$ \\
\hline$\Delta \mathrm{p}$ & & & $\begin{array}{c}0.307 \\
(0.302)\end{array}$ & \\
\hline Citation Year FE & Yes & Yes & Yes & Yes \\
\hline Book FE & Yes & Yes & No & Yes \\
\hline $\begin{array}{l}\text { Field FE * Citation } \\
\text { year FE }\end{array}$ & No & Yes & No & No \\
\hline Publication year FE & No & No & Yes & No \\
\hline Field FE & No & No & Yes & No \\
\hline R-squared & 0.562 & 0.624 & 0.205 & \\
\hline $\mathrm{N}$ & 9,302 & 9,302 & 9,302 & 7,088 \\
\hline Pre-1942 Mean & .284 & .284 & .284 & .284 \\
\hline \multicolumn{5}{|c|}{ Standard errors in parentheses clustered at the book level. ${ }^{* * *} \mathrm{p}<0.01,{ }^{*} \mathrm{p}<0.05,{ }^{*} \mathrm{p}<0.1$} \\
\hline
\end{tabular}

Notes: BRP and Swiss books are matched using the Mahalanobis propensity score algorithm with fields and pre-1942 average non-English language citations per year as matching variables. The dependent variable measures citations to book $i$ per year $t$ between 1920 and 1970. Columns (1-3) estimate OLS. Column (7) estimates quasi-maximum likelihood (QML) Poisson regressions to address the count data characteristics of citations. The indicator $B R P$ equals 1 for 214 books that were licensed to US publishers under the 1942 Book Republication Program (BRP). The control group covers 39 Swiss books that were not available for licensing due to Switzerland's neutrality during the war. The variable post equals for years after 1941. The variable $\Delta p$ measures the difference between the original price and the BRP price for book $i$, divided by the original price. 


\begin{tabular}{lccc}
\hline \hline & $(1)$ & $(2)$ & $(3)$ \\
\hline English & $-0.035^{* *}$ & $-0.035^{* *}$ & $-0.035^{* *}$ \\
BRP & $(0.014)$ & $(0.015)$ & $(0.014)$ \\
& & & 0.111 \\
English x BRP & 0.002 & 0.002 & $(0.103)$ \\
& $(0.048)$ & $(0.046)$ & 0.002 \\
BRP x post & 0.071 & 0.103 & $0.048)$ \\
& $(0.047)$ & $(0.075)$ & $(0.057)$ \\
English x post & $0.115^{* *}$ & $0.115^{* *}$ & $0.115^{* *}$ \\
& $(0.045)$ & $(0.048)$ & $(0.045)$ \\
English x BRP x post & -0.140 & -0.140 & -0.140 \\
& $(0.109)$ & $(0.107)$ & $(0.108)$ \\
BRP x $\Delta$ p x post & 0.101 & 0.077 & 0.170 \\
& $(0.193)$ & $(0.235)$ & $(0.189)$ \\
English x BRP x $\Delta \mathrm{p}$ x post & $1.276^{* * *}$ & $1.276^{* *}$ & $1.276^{* * *}$ \\
& $(0.402)$ & $(0.468)$ & $(0.400)$ \\
$\Delta \mathrm{p}$ & & & 0.181 \\
& & & $(0.246)$ \\
Citation Year FE & Yes & Yes & Yes \\
Book FE & Yes & Yes & No \\
Field * year FE & No & Yes & No \\
Pub. year \& Field FE & No & No & Yes \\
R-squared & 0.383 & 0.424 & 0.155 \\
N & 18,604 & 18,604 & 18,604 \\
Ste-1942 Meandard errors in parentheses clustered at the book level. $* * *$ & $.300 .01, * * \mathrm{p}<0.05, * \mathrm{p}<0.1$ \\
\hline \hline
\end{tabular}

Notes: BRP and Swiss books are matched using the Mahalanobis propensity score algorithm with fields and pre-1942 average non-English language citations per year as matching variables. The dependent variable measures citations to book $i$ per year $t$ and language $c$ (English vs. other) between 1920 and 1970. The indicator BRP equals 1 for 283 books that were licensed to US publishers under the 1942 Book Republication Program (BRP). The control group covers 247 Swiss books that were not available for licensing due to Switzerland's neutrality during the war. The variable post equals for years after 1941. The variable $\Delta p$ measures the difference between the original price and the BRP price for book $i$, divided by the original price. 


\begin{tabular}{lcccccc}
\hline \hline & $(1)$ & $(2)$ & $(3)$ & $(4)$ & $(5)$ & $(6)$ \\
\hline & & & & & & \\
English & -0.036 & -0.034 & -0.034 & -0.036 & -0.034 & -0.034 \\
& $(0.042)$ & $(0.039)$ & $(0.042)$ & $(0.042)$ & $(0.039)$ & $(0.042)$ \\
English x post & 0.079 & $0.115^{*}$ & $0.103^{* *}$ & -0.074 & -0.058 & -0.072 \\
& $(0.053)$ & $(0.063)$ & $(0.052)$ & $(0.091)$ & $(0.120)$ & $(0.091)$ \\
English x Math x post & $0.674^{* *}$ & $0.565^{* *}$ & $0.629^{* *}$ & & & \\
& $(0.279)$ & $(0.218)$ & $(0.266)$ & & & \\
English x $\Delta \mathrm{p}$ x post & & & & $0.646^{* *}$ & $0.706^{* *}$ & $0.650^{* *}$ \\
& & & & $(0.288)$ & $(0.266)$ & $(0.294)$ \\
English x Math x $\Delta \mathrm{p}$ x post & & & & $2.383^{* * *}$ & $2.110^{* *}$ & $2.588^{* * *}$ \\
& & & & $(0.907)$ & $(0.887)$ & $(0.930)$ \\
$\Delta \mathrm{p}$ & & & & & 0.286 \\
& & & & & $(0.178)$ \\
Citation Year FE & Yes & Yes & Yes & Yes & Yes & Yes \\
Book FE & Yes & Yes & No & Yes & Yes & No \\
Field * Citation year FE & No & Yes & No & No & Yes & No \\
Publication year FE & No & No & Yes & No & No & Yes \\
Field FE & No & No & Yes & No & No & Yes \\
R-squared & 0.367 & 0.407 & 0.126 & 0.382 & 0.422 & 0.160 \\
N & 19,680 & 19,162 & 19,162 & 18,986 & 18,524 & 18,524 \\
Pre-1942 Mean & 0.263 & 0.268 & 0.268 & 0.268 & 0.269 & 0.269 \\
Standard errors in parentheses clustered at the book level. *** p<0.01, ** p $<0.05, * \mathrm{p}<0.1$ \\
\hline \hline
\end{tabular}

Notes: The dependent variable measures citations to book $i$ per year $t$ between 1920 and 1970 . The indicator English equals 1 for citations by English-language authors; the control group are citations to the same book from authors in other languages. The variable post indicates years after 1941, and Math indicates 55 books in mathematics. The variable $\Delta p$ measures the difference between the original price and the BRP price for book $i$, divided by the original price. 
(1) (2)

(3)

(4)

Within 25 miles * post

$0.798 *$

$(0.481)$

Within 50 miles * post

Within 75 miles * post

25-50 miles * post

50-75 miles * post

75-100 miles * post

Year FE

Location FE

R-squared

$\mathrm{N}$

Pre-1942 Mean

Yes

0.504

9,180

0.358

\begin{tabular}{lccc} 
& & $0.808^{*}$ & \\
& & $(0.467)$ & \\
& & & \\
& & & 0.890 \\
& & & $0.613)$ \\
& & & $(0.599)$ \\
& & & -0.778 \\
& & & $(0.553)$ \\
Yes & & Yes & Yes \\
Yes & Yes & Yes & Yes \\
0.504 & 0.504 & 0.504 & 0.507 \\
9,180 & 9,180 & 9,180 & 9,180 \\
0.358 & 0.358 & 0.358 & 0.358 \\
clustered at the location level. $* * * \mathrm{p}<0.01, * * \mathrm{p}<0.05, * \mathrm{p}<0.1$ \\
\hline
\end{tabular}

Notes: The dependent variable measures the number of new PhDs in mathematics at location $k$ in year $t$. The indicator within $x$ miles equals 1 for locations that are within $x$ miles of a library with at least one BRP math book. The indicator $x$-y miles equals 1 for locations that are further between $x$ and $y$ miles away from a library with BRP books. The variable post equals 1 for years after 1941. 